\title{
Probing interactions through space using spin-spin coupling
}

\author{
Martin W. Stanford,${ }^{a}$ Fergus R. Knight, ${ }^{a}$ Kasun S. Athukorala Arachchige, ${ }^{a}$ Paula Sanz Camacho, ${ }^{a}$ \\ Sharon E. Ashbrook, ${ }^{a}$ Michael Bühl, ${ }^{a}$ Alexandra M. Z. Slawin ${ }^{a}$ and J. Derek Woollins*a \\ Received (in $X X X, X X X)$ Xth $X X X X X X X X X 20 X X$, Accepted Xth XXXXXXXXX 20XX \\ ${ }_{5}$ DOI: 10.1039/b000000x
}

The series of eight 5-(TeY)-6-(SePh)acenaphthenes ( $\mathrm{Y}=\mathrm{Fp}(\mathbf{2})$, Tol (3), An- $p$ (4), An-o (5), Tp (6), Mes (7), Tip (8), Nap (9)) were prepared and structurally characterised by X-ray crystallography, solution and solid-state NMR spectroscopy and density functional theory (DFT/B3LYP) calculations. All members of the series, except $\mathbf{5}$, adopt a BA type configuration comparable to the parent compound $\mathbf{1}(\mathrm{Y}=\mathrm{Ph})$,

10 aligning the $\mathrm{Te}-\mathrm{C}_{\mathrm{Y}}$ bond along the mean acenaphthene plane and promoting a nonbonded $\mathrm{Se} \cdots \mathrm{Te}-\mathrm{C}_{\mathrm{Y}} 3 \mathrm{c}-$ $4 \mathrm{e}$ type interaction to form to stabilise the molecule (G-dependence). 5 ( $\mathrm{Y}=\mathrm{An}-o$ ) adopts a BC type conformation in the solid but DFT calculations show this optimises to BA. Indication of strong throughspace peri-interactions between Te and Se are observed in the ${ }^{77} \mathrm{Se}$ and ${ }^{125} \mathrm{Te}$ NMR spectra, with $J(\mathrm{Te}, \mathrm{Se})$ spin-spin coupling constants (SSCCs) in the range -688 to $-748 \mathrm{~Hz}$. Evidence supporting the presence of

15 this interaction was also found in solid-state NMR spectra of some of the compounds which exhibit an indirect spin-spin coupling on the same order of magnitude as observed in solution. In order to quantify the steric bulk of the aryl groups $(\mathrm{Y})$, we introduce the crystallographic steric parameter $(\theta)$, the cone angle measured from the furthest $\mathrm{H}$ atoms lying on the edges of the cone to the Te atom located at its vertex. Modification to $\mathrm{Y}$ has no apparent influence over the conformation of the molecule, the degree of 20 molecular distortion occurring in the acenaphthene backbone or the extent of $3 \mathrm{c}-4 \mathrm{e}$ interaction; peridistances for all eight compounds are within $0.08 \AA$ and no apparent correlation is observed between the steric bulk of Y $(\theta)$ and the ${ }^{77} \mathrm{Se}$ chemical shifts or $J(\mathrm{Te}, \mathrm{Se}) \mathrm{SSCC}$. In contrast, a good correlation is found between $\theta$ and ${ }^{125}$ Te chemical shifts. DFT calculations performed on all members of the series confirm the comparable covalent bonding between Te and Se in the series, with WBIs of $c a .0 .1$ obtained. ${ }_{25}$ Natural bond orbital analysis shows a noticeable donor-acceptor interaction between a p-type lone pair on Se and a $\sigma^{*}(\mathrm{Te}-\mathrm{C})$ antibonding orbital, confirming the onset of $3 \mathrm{c}-4 \mathrm{e}$ type bonding.

\section{Introduction}

The magnitude of NMR spin-spin coupling constants (SSCCs) is dependent upon the interaction between the magnetic moments of 30 the coupling nuclei and can provide important information for analysing molecular structures. ${ }^{1-3}$ Indirect (scalar) coupling is transmitted by polarisation of the electrons in the succession of bonds connecting the nuclei (through-bond coupling) and generally diminishes as the number of bonds between the two 35 nuclei increases, with coupling beyond four bonds usually too small to be observed. ${ }^{1-3}$

Nevertheless, remarkably large coupling constants have been detected in molecules in which NMR active atomic nuclei lie many bonds apart but are located in close proximity (formally 40 nonbonded), with spin-spin coupling transmitted through the interaction of overlapping lone pairs (through-space coupling). ${ }^{3-8}$ Such spatial proximity can be achieved across the bay region in peri-substituted naphthalenes and related 1,2-dihydroacenaphthylenes (acenaphthenes), where large heteroatoms, fixed 45 by the rigid organic framework, have typical separations of around $3 \AA .{ }^{9}$ For instance, surprisingly large $J\left({ }^{19} \mathrm{~F},{ }^{19} \mathrm{~F}\right)$ SSCCs, long known to exist between intramolecularly confined fluorine atoms, have been observed in peri-difluoronaphthalenes (A \& $\mathbf{B}$ Figure $1 ; 65-85 \mathrm{~Hz}$ ), the magnitude attributed to a significant ${ }^{19} \mathrm{~F}$ -

${ }_{50}^{19} \mathrm{~F}$ through-space coupling component and directly dependent upon the internuclear $\mathrm{F} \cdots \mathrm{F}$ distance. ${ }^{5,6}$ Exceptionally large ${ }^{4} \mathrm{~J}\left({ }^{31} \mathrm{P},{ }^{31} \mathrm{P}\right)$ coupling constants have similarly been observed in 1,8-diphosphanaphthalenes (C Figure 1) which also represent systems possessing lone pairs available for interaction through 55 space. ${ }^{7,10,11}$ In fact the values reported for $\mathrm{Nap}\left[\mathrm{P}\left(\mathrm{NMe}_{2}\right)_{2}\right]\left[\mathrm{P}(\mathrm{OMe})\left(\mathrm{NMe}_{2}\right)\right] \quad(246 \mathrm{~Hz}),{ }^{10} \mathrm{Nap}\left(\mathrm{PH}_{2}\right)_{2} \quad(222$ $\mathrm{Hz})^{7}$ and $\mathrm{Nap}\left(\mathrm{PPh}_{2}\right)_{2}(199 \mathrm{~Hz}$; obtained from MAS solid state ${ }^{31} \mathrm{P}\left\{{ }^{1} \mathrm{H}\right\}$ NMR spectrum $)^{11}$ are more in line with ${ }^{1} J$-couplings found in systems with conventional P-P bonds $(180-230 \mathrm{~Hz}){ }^{10}$ ${ }_{60} J\left({ }^{77} \mathrm{Se},{ }^{77} \mathrm{Se}\right)$ nuclear couplings have also been investigated in detail through quantum chemical (QC) calculations ${ }^{8}$ in order to investigate the nature of bonded and nonbonded interactions between Se atoms in peri-substituted naphthalenes. Notably large ${ }^{4} J$-couplings were observed in $\mathrm{Se} \cdots \mathrm{Se}(332 \mathrm{~Hz}), \mathrm{Se} \cdots \mathrm{Se}=\mathrm{O}(189$ ${ }_{65} 200 \mathrm{~Hz}$ ) and $\mathrm{O}=\mathrm{Se} \cdots \mathrm{Se}=\mathrm{O}(456 \mathrm{~Hz})$ derivatives $(\mathbf{D} \&$ E Figure $1)$, with the latter the largest known value for ${ }^{4} J$-coupling between two formally nonbonded Se atoms. ${ }^{8}$ 
<smiles>[Y]c1ccc(F)c2c(F)ccc([Y])c12</smiles>

A<smiles>[Y][Se](C)(C)c1cccc2cccc([As](C)=[V])c12</smiles>

D<smiles>C[C@H](c1ccccc1)c1cccc2cccc(CPc3ccccc3)c12</smiles>

G<smiles>[Y]c1ccc(F)c2c(F)ccc([Y])c12</smiles>

B<smiles>[Y][Se](=[W])c1cccc2cccc([Se](=[V])Pc3ccccc3)c12</smiles>

E

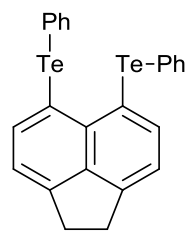

H<smiles>[R20]c1cccc2cccc(P)c12</smiles>

C<smiles>C[C@H](c1ccccc1)c1ccc2c3c(ccc(CPc4ccccc4)c13)CC2</smiles>

$\mathbf{F}$

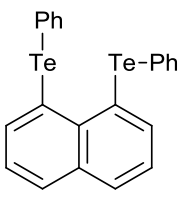

I
Fig. 1 Naphthalene and acenaphthene motifs allowing for the overlap of lone-pair orbitals leading to through-space coupling interactions.

Considering spin polarisation and therefore the value of the 5 through-space coupling is dependent upon the spatial distribution of electron density between the coupling nuclei, SSCCs provide a convenient method of analysing the electronic structure of a system and can indicate the onset of intramolecular bonding interactions. For many years we have been investigating non10 covalent interactions which prevail when pnictogen and chalcogen congeners are located at the peri-positions of naphthalene and acenaphthene. ${ }^{12-21}$ Under appropriate geometric conditions, weak donor-acceptor interactions can transpire leading to $3 \mathrm{c}-4 \mathrm{e}$ type bonding, which becomes more prevalent as 15 larger atoms occupy the proximal positions. ${ }^{13-18,20}$ In all cases, peri-separations are well within the sum of van der Waals radii for the two substituted heteroatoms and Wiberg bond indices ${ }^{22}$ of up to ca. 0.15 have been computed for bis-tellurium derivatives (F \& G Figure 1). ${ }^{17}$ Direct observation of strong through-space ${ }_{20}$ peri-interaction is detected in the ${ }^{77} \mathrm{Se}$ and ${ }^{125} \mathrm{Te}$ NMR spectra of unsymmetrical Acenap $(\mathrm{TePh})(\mathrm{SePh})(\mathbf{1}$, Figure 2) and its naphthalene analogue, which display exceptionally large, formally ${ }^{4} J$, SSCCs of $-716 \mathrm{~Hz}$ and $-834 \mathrm{~Hz}$, respectively. ${ }^{17,18}$ Even larger WBIs up to 0.18 are obtained for the cationic salts 25 formed by methylation of the neutral chalcogen substituted compounds (H \& I Figure 1), and these too exhibit considerable through-space coupling $\left[J\left({ }^{77} \mathrm{Se},{ }^{77} \mathrm{Se}\right) \quad\right.$ H $141, \quad$ I $167 \quad \mathrm{~Hz}$; $J\left({ }^{125} \mathrm{Te},{ }^{77} \mathrm{Se}\right) \mathbf{H ~} 382$, I $429 \mathrm{~Hz} ; J\left({ }^{125} \mathrm{Te},{ }^{125} \mathrm{Te}\right) \mathbf{H} 946$, I 1093 $\mathrm{Hz} .^{18,23}$

30 We have recently reported even greater SSCCs in symmetrical bis-tellurium systems Acenap $(\mathrm{TePh})_{2}(2110 \mathrm{~Hz})$ and $\mathrm{Nap}(\mathrm{TePh})_{2}$ $(2505 \mathrm{~Hz}),{ }^{24}$ in which weak donor-acceptor interactions, marking the onset of $3 \mathrm{c}-4 \mathrm{e}$ bonding, greatly enhance the Te,Te couplings and thus contribute to the magnitude of the $J\left({ }^{125} \mathrm{Te},{ }^{125} \mathrm{Te}\right)$ ${ }^{35}$ values. ${ }^{20}$ The large discrimination between the $J$ values in these two analogues, however, suggests the effective overlap of the tellurium lone-pairs and hence the size of the SSCCs, depends not only on the intramolecular Te...Te peri-distance, but also on the orientation of the lone-pairs, similar to reported angular 40 dependence found in FF and SeSe systems. ${ }^{5,8}$ Detailed conformational analyses carried out on the related bis-tellurium compound $\mathrm{Nap}(\mathrm{TeMe})_{2}{ }^{20}$ and bis-selenium derivatives ${ }^{8}$ have shown that a minor change in conformation can result in a dramatic change in the magnitude of SSCCs, for example a 45 structure with $\mathrm{CC} t$ conformation (vide infra) ${ }^{25,26}$ would have a $J$ value of around $2500 \mathrm{~Hz}$, similar to what is found for $\mathrm{Nap}(\mathrm{TePh})_{2}$, whilst a structure in the $\mathrm{AB}$ region, as adopted by Acenap $(\mathrm{TePh})_{2},{ }^{17}$ would be much lower (ca. $\left.1500 \mathrm{~Hz}\right){ }^{20}$ This characteristic of SSCCs to act as a sensitive probe for 50 distinguishing between differing conformers of a molecule is a new facet of through-space spin-spin coupling, and one worth further investigation. In the present study, we explore how substituents at the phenyl ring affect the bonding interactions and hence the value of SSCCs in a series of mixed Te,Se 55 acenaphthenes Acenap(TeY)(SePh) (Y = Fp 2; Tol 3; An-p 4; An-o 5; Tp 6; Mes 7; Tip 8; Nap 9; Figure 2) compared with the parent phenyl substituted compound $\mathbf{1} .^{17}$

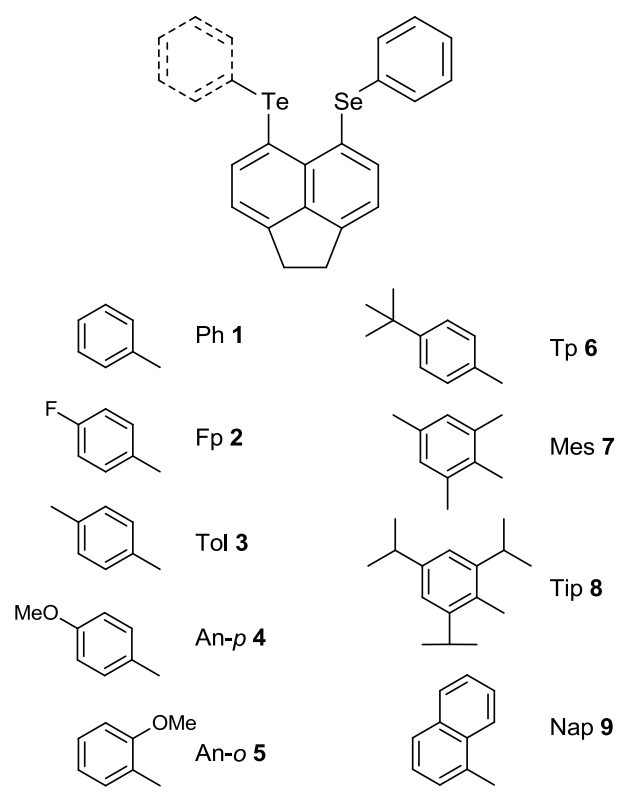

Fig. 2 5-(aryltelluro)-6-(phenylselenyl)acenaphthenes 1-9

\section{${ }_{60}$ Results and Discussion}

Synthesis of 5-(aryltelluro)-6-(phenylselenyl)acenaphthenes 29: The eight mixed tellurium-selenium substituted acenaphthenes 2-9 were prepared following the same procedure to that previously reported for the synthesis of 5-(phenyltelluro)-665 (phenylselenyl)acenaphthene $\mathbf{1} ;{ }^{17}$ under an oxygen- and a moisture-free nitrogen atmosphere, 5-bromo-6(phenylselenyl)acenaphthene was independently treated with a single equivalent of $n$-butyllithium in diethyl ether to afford the precursor 5-(lithio)-6-(phenylselanyl)acenaphthene, which when 70 reacted with the respective diaryl ditelluride [bis(4-fluorophenyl) ditelluride (FpTeTeFp), bis(4-methylphenyl) ditelluride (TolTeTeTol), bis(4-methoxyphenyl) ditelluride (An- $p$ TeTeAn$p$ ), bis(2-methoxyphenyl) ditelluride (An-oTeTeAn-o), bis(4- 


\section{Cite this: DOI: $10.1039 / \mathrm{c} 0 x x 00000 x$}

Table $1{ }^{77}$ Se and ${ }^{125}$ Te NMR spectroscopy data and the crystallographic steric parameter $(\theta)$

\begin{tabular}{|c|c|c|c|c|c|c|c|c|c|}
\hline & $\mathbf{1}^{17}$ & 2 & 3 & 4 & 5 & 6 & 7 & 8 & 9 \\
\hline Aryl Group & $\mathbf{P h}$ & Fp & Tol & An- $p$ & An-o & $\mathbf{T p}$ & Mes & Tip & Nap \\
\hline${ }^{77}$ Se NMR & 341 & 340 & 342 & 342 & 347 & 343 & 345 & 345 & 400 \\
\hline${ }^{125}$ Te NMR & 663 & 653 & 649 & 639 & 544 & 643 & 428 & 376 & 552 \\
\hline$J\left({ }^{125} \mathrm{Te}-{ }^{77} \mathrm{Se}\right)$ & -716 & -726 & -723 & -722 & -748 & -723 & -711 & -688 & -724 \\
\hline$J\left({ }^{125} \mathrm{Te}-{ }^{77} \mathrm{Se}\right)(\text { comp. })^{b}$ & $-526^{c}$ & -484 & -471 & -537 & -585 & -468 & -519 & -469 & -460 \\
\hline $\boldsymbol{\theta}$ & 81.22 & 80.98 & 80.43 & 81.02 & 103.34 & 80.46 & 121.55 & 134.98 & 102.8 \\
\hline
\end{tabular}

${ }^{a}$ All spectra run in $\mathrm{CDCl}_{3} ; \delta(\mathrm{ppm}), J(\mathrm{~Hz}), \theta\left({ }^{\circ}\right) ;{ }^{b}$ Computed at the ZORA-SO/BP86/TZ2P level; ${ }^{c}$ ZORA-SO/PBE0 level: $J=-571 \mathrm{~Hz}$.

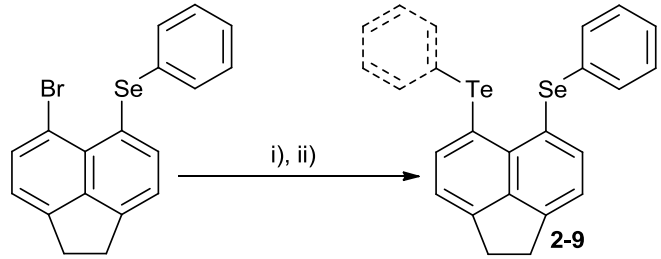

Scheme 1 The preparation of 5-(aryltelluro)-6-

5 (phenylselenyl)acenaphthenes 2-9: (i) $n \mathrm{BuLi}\left(1\right.$ equiv), $\mathrm{Et}_{2} \mathrm{O},-78{ }^{\circ} \mathrm{C}, 1 \mathrm{~h}$; (ii) ArylTeTeAryl (1 equiv), $\mathrm{Et}_{2} \mathrm{O},-78^{\circ} \mathrm{C}, 1 \mathrm{~h}$ (Aryl: Ph 1; Fp 2; Tol 3; An- $p$ 4; An-o 5; Tp 6; Mes 7; Tip 8; Nap 9).

tertbutylphenyl) ditelluride (TpTeTeTp), bis(2,4,6trimethylphenyl) ditelluride (MesTeTeMes), bis(2,4,610 triisopropanylphenyl) ditelluride (TipTeTeTip) and bis(1naphthyl) ditelluride (NapTeTeNap)] afforded 2-9 in moderate to good yield [yield: 43 (2), 42 (3), 69 (4), 67 (5), 23 (6), 18 (7), 56 (8), 86\% (9); Scheme 1]. All compounds obtained (2-9) were characterized by multinuclear magnetic resonance and IR 15 spectroscopies and mass spectrometry, and the homogeneity of the new compounds was confirmed by microanalysis. Solutionand solid-state ${ }^{77} \mathrm{Se}$ and ${ }^{125} \mathrm{Te}$ NMR spectroscopic data for the series of acenaphthene derivatives is displayed in Table 1.

Solution- and Solid-State NMR Studies: As expected, the ${ }_{20}{ }^{77}$ Se NMR and ${ }^{125}$ Te NMR spectra for all nine compounds exhibit single peaks, with satellites attributed to ${ }^{125} \mathrm{Te}-{ }^{77} \mathrm{Se}$ coupling. The relatively large $J$ values $(-687 \mathrm{~Hz}(8)$ to $-749 \mathrm{~Hz}(5))$ indicate a potential weakly attractive through-space interaction between $\mathrm{Te}$ and $\mathrm{Se}$ in each case, however, the range of values lie within 62 ${ }_{25} \mathrm{~Hz}$ and there is no discernible correlation with the steric bulk of the Te(aryl) moiety. The negative sign attributed to the experimental $J$ values is taken from the computed $J$ values for the Te,Se systems and stems from the opposite signs of the gyromagnetic ratios of ${ }^{77} \mathrm{Se}\left(5.12 \times 10^{7} \mathrm{rad} \mathrm{T}^{-1} \mathrm{~s}^{-1}\right)$ and ${ }^{125} \mathrm{Te}(-$ $\left.308.51 \times 10^{7} \mathrm{rad} \mathrm{T}^{-1} \mathrm{~s}^{-1}\right)$. $^{2}$

Compared to experiment, the computed ${ }^{27} J\left({ }^{125} \mathrm{Te},{ }^{77} \mathrm{Se}\right) \mathrm{SSCCs}$ are significantly underestimated $(-460 \mathrm{~Hz}$ to $-585 \mathrm{~Hz})$. The theoretical $J$ values are mildly dependent on the functional employed in the NMR calculation, becoming slightly more 35 negative on going from BP86 to PBE0 (e.g. by $-45 \mathrm{~Hz}$ for $\mathbf{1}$, Table 1). Theory and experiment agree that the $J\left({ }^{125} \mathrm{Te},{ }^{77} \mathrm{Se}\right)$ couplings should be much smaller than the corresponding $\left({ }^{125} \mathrm{Te},{ }^{125} \mathrm{Te}\right)$ couplings in ditelluride derivatives. At the same level (BP86), a $J\left({ }^{125} \mathrm{Te},{ }^{125} \mathrm{Te}\right)$ value of $1543 \mathrm{~Hz}$ was predicted for ${ }_{40}$ Acenap $(\mathrm{TePh})_{2}$, with $J\left({ }^{123} \mathrm{Te},{ }^{125} \mathrm{Te}\right) 1750 \mathrm{~Hz}$ detected as satellites in the ${ }^{123} \mathrm{Te}$ NMR spectrum, corresponding to $2110 \mathrm{~Hz}$ in $J\left({ }^{125} \mathrm{Te},{ }^{125} \mathrm{Te}\right) .{ }^{20}$ The computed reduced coupling constant (K) gives a more direct comparison of couplings involving different sets of nuclei. ${ }^{28}$ Upon moving down one row in the periodic table ${ }_{45} \mathrm{~K}$ increases significantly, nearly doubling from $K=720 \cdot 10^{19} \mathrm{~kg}$ $\mathrm{m}^{-2} \mathrm{~s}^{-2} \mathrm{~A}^{-2}$ in Acenap(TePh) $(\mathrm{SePh})$ to $K=1273 \cdot 10^{19} \mathrm{~kg} \mathrm{~m}^{-2} \mathrm{~s}^{-2} \mathrm{~A}^{-2}$ in Acenap $(\mathrm{TePh})_{2}$ (computed for BA conformers). ${ }^{20}$ The Fermi contact mechanism, whereby two coupling nuclei are in contact via the s-electrons of the bonds linking them, is widely 50 considered the dominant factor in spin-spin coupling ${ }^{2}$ and has been confirmed to govern the (Te,Te) coupling constants in Acenap $(\mathrm{TePh})_{2} \cdot{ }^{20}$ The same is found for compounds $\mathbf{1}-\mathbf{9}$ of this study, where diamagnetic spin-orbit contributions are negligible and paramagnetic spin-orbit contributions are less than $14 \mathrm{~Hz}$ at 55 the ZORA-SO level. The magnitude of the coupling constant is thus influenced by the extent of s-orbital participation in the bonding and the polarisability of the s-electrons, which is controlled by the spin of the respective nuclei involved. ${ }^{2}$ The natural increase in the polarisability of valence s-electrons down 60 the periodic table thus explains the dramatic difference observed between (Te,Se) and (Te,Te) coupling constants (and similarly for the reduced coupling constants, $\mathrm{K}$ ), with significantly reduced $J$ values expected between lighter congeners.

A further consideration for molecules in which heteroatoms 65 are held in close proximity, but formally non-bonded, is the degree to which the observed coupling results from a direct overlap of lone pair orbitals (through-space coupling). The structural configuration of the molecule thus influences the degree to which electron density is delocalized over the formally

70 nonbonded atoms, and hence the contribution to the bonding occurring between these atoms. ${ }^{5,8,20}$ The propensity for compounds 1-9 to adopt the BA configuration ${ }^{25,26}$ is thus partly responsible for the smaller $J(\mathrm{Te}, \mathrm{Se})$ couplings compared to $J(\mathrm{Te}, \mathrm{Te})$, whilst further reduction is likely due to the decreased 75 multicenter bonding compared to the bis-tellurium systems (vide infra).

The small range of ${ }^{77}$ Se NMR chemical shifts for 1-8 ( 8 ppm) reveals the chemical similarity of the Se nuclei throughout the series and suggests the change in size of the Te(aryl) group has a ${ }_{80}$ limited effect on the chemical shielding of the Se nucleus. The 


\section{Cite this: DOI: $10.1039 / \mathrm{c0xx} 00000 x$}

ARTICLE TYPE

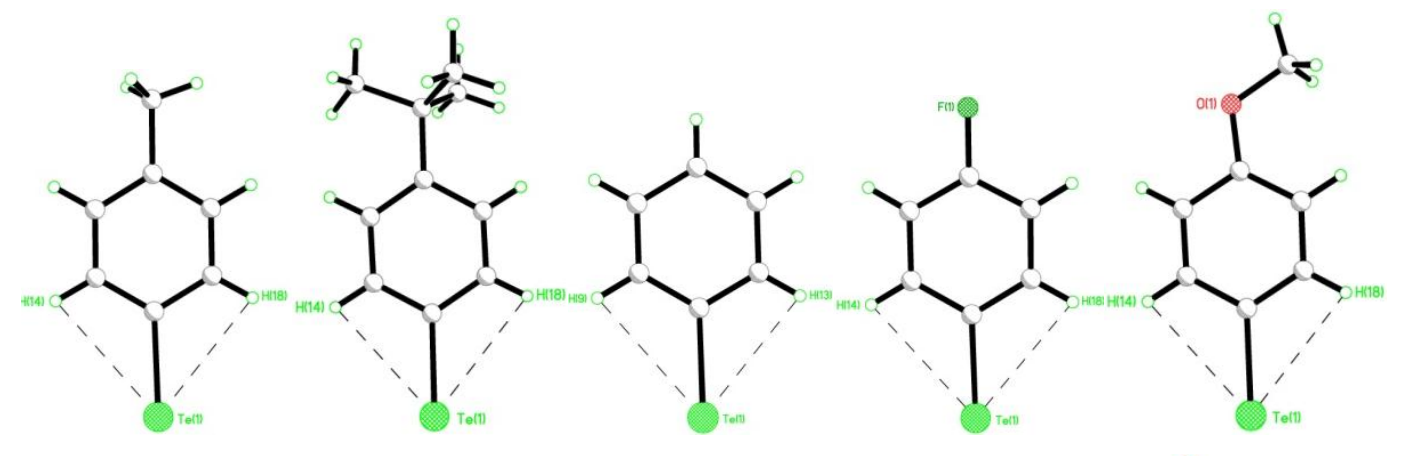

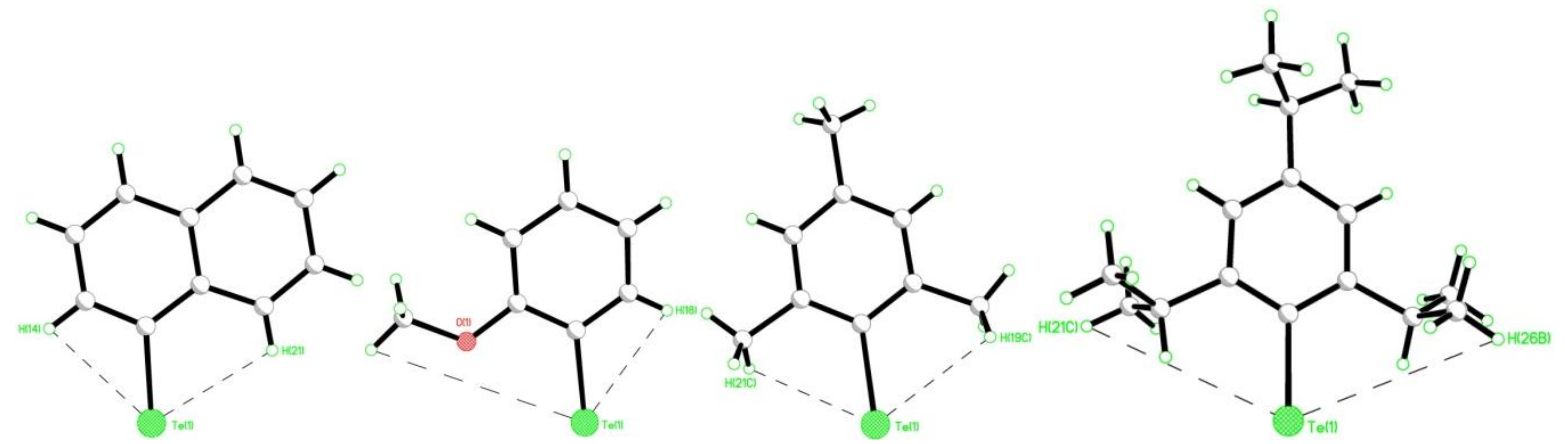

Fig. 3 The Te(aryl) moieties of 1-9 illustrating the crystallographic steric parameter $\theta$ defined by the largest measurable H-Te-H cone angle.

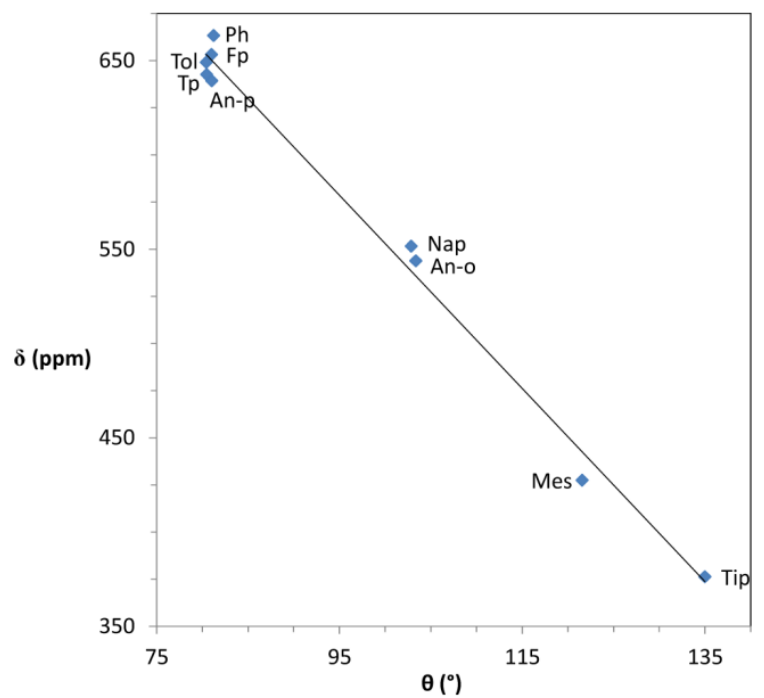

$5 \quad$ Fig. 4 Plot of ${ }^{125}$ Te NMR chemical shifts against the crystallographic steric parameter $\theta$ using data from Table 1 for compounds 1-9.

one exception in the series is compound 9 (TeNap) which displays a notable downfield shift to $399.9 \mathrm{ppm}$, compared with the remaining members of the series (340-347 ppm). In contrast, 10 modification of the size and electronics of the aryl moiety has a greater influence on the ${ }^{125}$ Te NMR signals, which are generally shifted upfield (to lower chemical shift) as less encumbered groups on Te are replaced by much bulkier ones ( 1 phenyl 663.4 ppm; 8 triisopropylphenyl (Tip) 376.4ppm).
${ }_{15}$ In order to correlate the ${ }^{125}$ Te NMR chemical shifts with the steric bulk of the aryl functionalities, Te(aryl) group cone angles have been calculated from crystallographic data to provide a quantitative measure of the steric bulk. The steric parameter $(\theta)$, which is a slight modification of the Tolman Cone Angle, ${ }^{29}$ is

20 defined by the apex angle measured from the hydrogen atoms occupying the extreme edges of a cone to the centre of the Te atom located at its vertex. Figure 3 illustrates the increasing steric bulk for the Te(aryl) groups in compounds 1-9 as defined by the magnitude of the steric parameter $(\theta)$.

${ }_{25}{ }^{125}$ Te NMR data for 1-9 plotted against $\theta$ show a good correlation between chemical shift magnitude and the size of the Te(aryl) group (Figure 4). The large range of tellurium chemical shifts in the present series can therefore be explained in terms of steric crowding, despite the apparent similarity of the aryl group 30 electronegativities. A similar observation has previously been observed in tertiary phosphines, with a good correlation between the Tolman cone angle and ${ }^{31} \mathrm{P}$ NMR shifts. ${ }^{29}$

${ }^{77} \mathrm{Se}$ and ${ }^{125} \mathrm{Te}$ solid-state NMR spectra were recorded for compounds $\mathbf{6}$ and $\mathbf{8}$, and the splittings observed for both 35 compounds confirm the presence of a weak interaction between Se and Te. However, the presence of a significant chemical shift anisotropy (CSA) in both cases results in a number of spinning sidebands, hindering the accurate analysis of both shielding and coupling tensors. The splittings observed in the isotropic peak are 40 between 640 and $700 \mathrm{~Hz}$ in both cases, although a more detailed analysis would be required to extract the full information on both interactions. As an example the ${ }^{77} \mathrm{Se}$ and ${ }^{125} \mathrm{Te}$ spectra of 
compound $\mathbf{8}$ are shown in Figures 5 and 6.

Crystal structures of compounds $\mathbf{8}$ and $\mathbf{6}$ contain one crystallographically distinct molecule per asymmetric unit, however, two isotropic peaks were found for both samples due to 5 maybe the presence of some impurities present in the bulk material.

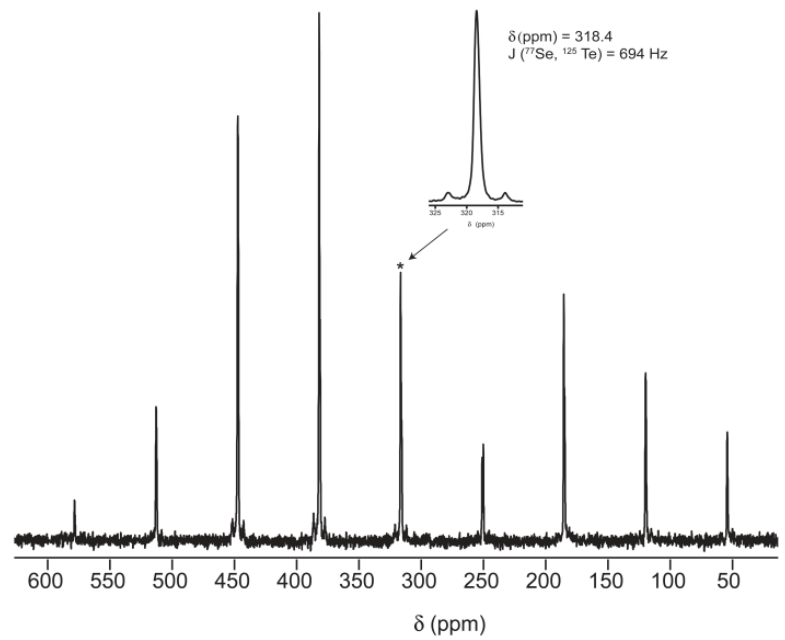

Fig. $5{ }^{77} \mathrm{Se}$ solid-state $(\mathrm{B} 0=9.4 \mathrm{~T}) \mathrm{NMR}$ spectra of compound $\mathbf{8}$, recorded using an MAS rate of $5 \mathrm{kHz}$ for the full spectrum and $40 \mathrm{kHz}$ 10 for the expanded view of the isotropic peak (indicated by *). The values quoted correspond to the isotropic chemical shift and the splitting observed in the isotropic peak.

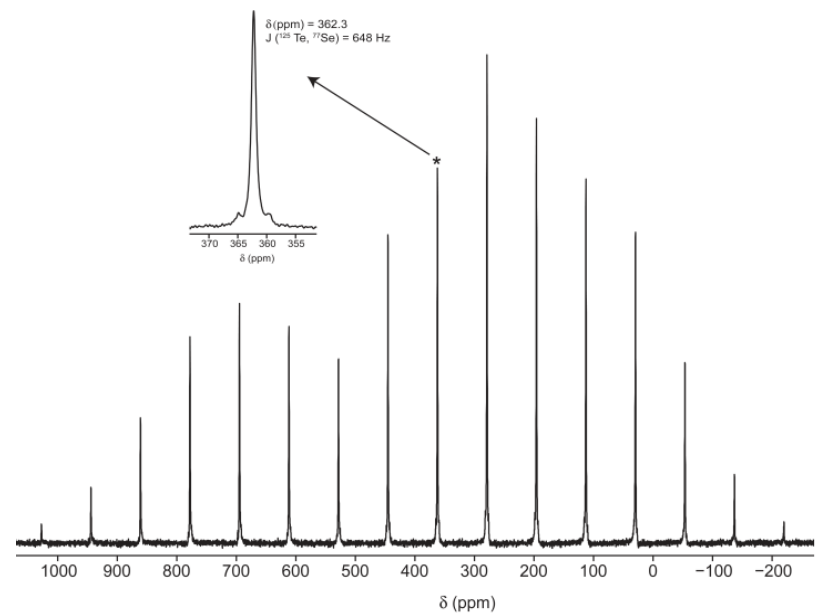

Fig. $6{ }^{125}$ Te solid-state $(B 0=9.4 \mathrm{~T})$ NMR spectra of compound $\mathbf{8}$,

15 recorded using an MAS rates of $10.5 \mathrm{kHz}$. The values quoted correspond to the isotropic chemical shift and the splitting observed in the isotropic peak (also shown expanded).

\section{X-ray investigations}

Suitable single crystals were obtained for 2-9 by diffusion of 20 hexane into a saturated solution of the compound in dichloromethane. Compounds $\mathbf{3}$ and $\mathbf{5}$ crystallise with virtually identical molecules in the asymmetric unit, in contrast to the remaining members of the series which contain one molecule in the asymmetric unit. Selected interatomic bond lengths and 25 angles and computational properties are listed in Tables 2-6. Further crystallographic information can be found in the Supporting Information.

Molecular structures of peri-substituted systems are conveniently classified by three types $\mathrm{A}, \mathrm{B}$ and $\mathrm{C}$, describing the 30 conformation of the $\mathrm{E}_{-} \mathrm{C}_{\mathrm{Ar}}$ bond with respect to the mean naphthalene plane as either perpendicular $(\mathbf{A})$, along the plane $(\mathbf{B})$ or intermediate between these two scenarios $(\mathbf{C})$. A double substitution of aryl functionalities can subsequently align either cis (c) or trans $(t)$ relative to the naphthalene plane. ${ }^{17,25}$ The labels 35 planar (pl), perpendicular (pd) and non-planar/non-perpendicular (np) are additionally employed to describe the conformation around the $\mathrm{E}_{-} \mathrm{C}_{\mathrm{Ar}}$ bond. ${ }^{25}$ The absolute conformation of aromatic rings is calculated from torsion angles $\theta$ and $\gamma$, which define the degree of rotation around the $\mathrm{E}_{-} \mathrm{C}_{\mathrm{Acenap}}(\mathbf{A}, \mathbf{B}, \mathbf{C})$ and $\mathrm{E}-\mathrm{C}_{\mathrm{Ar}}(\mathbf{p l}$, ${ }_{40}$ pd, np) bonds, respectively (Table 6, Figure S2, ESI). ${ }^{17,25,26}$

The energy lowering effect of the $(\mathrm{G}) \cdots \sigma^{*}\left(\mathrm{E}-\mathrm{C}_{\mathrm{Ar}}\right) 3 \mathrm{c}-4 \mathrm{e}$ interaction has been shown to play an important role in controlling the fine structures of peri-substituted systems (Gdependence), ${ }^{13-18,20,25}$ although the sterics and electronics of the 45 aryl groups attached to the peri-atoms must also be considered (Y-dependence). ${ }^{25}$ Minor adjustments to the size and donor/acceptor properties of $\mathrm{Y}$ can have a dramatic affect on the structural conformation, forcing substituents to change between the extremes of a type A or B configuration. ${ }^{25}$

50 As mentioned above, compounds $\mathbf{2 - 9}$ prefer to adopt BA type configurations, illustrating the similar Y-dependence of the aryl groups involved, despite the notable change in steric bulk within the series (Table 6, Figure 7). In each case the Te- $\mathrm{C}_{\mathrm{Ar}}$ bond aligns along the acenaphthene plane (type B) and provides the correct ${ }_{55}$ geometry to promote delocalization of a selenium lone pair $(\mathrm{G})$ to the antibonding $\sigma^{*}(\mathrm{Te}-\mathrm{C})$ orbital, thus forming a weakly attractive $3 \mathrm{c}-4 \mathrm{e}$ type interaction (G-dependence). Se $\cdots \mathrm{Te}-\mathrm{C}_{\mathrm{Ar}}$ angles are in the range $162-173^{\circ}$ and nonbonded peri-distances are $\sim 18 \%$ shorter than the sum of van der Waals radii for Te and ${ }_{60} \mathrm{Se}(3.96 \AA) .{ }^{30}$ The elongation and weakening of the $\mathrm{Te}-\mathrm{C}_{\mathrm{Ar}}$ bonds (2.11-2.16 $\AA$ ) also provides support for the formation of hypervalent $3 \mathrm{c}-4 \mathrm{e}$ bonding interactions across the peri-gap. This is observed at the B3LYP level, where the Te- $\mathrm{C}_{\mathrm{Ph}}$ bond length increases from $2.131 \AA$ in $A c e n a p(T e P h)$ (with the same 65 conformation of the $\mathrm{Ph}$ group as in $\mathbf{1}$ ) to $2.154 \mathrm{~A}$ in $\mathbf{1}$. In addition, $\mathrm{Te}-\mathrm{C}_{\mathrm{Ar}}$ WBIs decrease noticeably in the sequence, from 0.94 to 0.86 , which is also consistent with the weakening of the Te$\mathrm{C}\left(\right.$ aryl) bond expected from the $\operatorname{lp}(\mathrm{Se}) \cdots \sigma^{*}\left(\mathrm{Te}-\mathrm{C}_{\mathrm{Ar}}\right)$ orbital interaction.

70 In general, the plane of the Te(aryl) group aligns perpendicular (pd) to the mean acenaphthene plane, although the $\mathrm{Te}$ (nap) group in 9 twists around the $\mathrm{Te}-\mathrm{C}_{\mathrm{Nap}}$ bond aligning the naphthalene plane neither perpendicular or coplanar (np) with the acenaphthene backbone. Compound 5 (Te-An-o) is the one 75 anomaly in the series, adopting a BC type configuration in which the $\mathrm{Se}(\mathrm{Ph})$ moiety aligns with a twist geometry $(\mathbf{C})$ with respect to the acenaphthene plane (Figure 8, Table 6). Computational conformational analysis, however, has shown that dramatically different conformations can have similar potential energies 80 (within $\sim 1 \mathrm{kcal} \mathrm{mol}^{-1}$ ), ${ }^{20}$ thus consistent with the structural variation found in the solid for compound $\mathbf{5}$ (see also below). In addition, density functional theory (DFT) calculations show that all members of the series, including $\mathbf{5}$, optimise to a BA conformation at the B3LYP/SDD/962(d)/6-31G(d) level. ${ }_{85}$ Throughout the series, the plane of the $\mathrm{Se}(\mathrm{Ph})$ moiety generally aligns coplanar (pl) with the acenaphthene ring, although pd and 


\section{Cite this: DOI: 10.1039/c0xx00000x}

ARTICLE TYPE
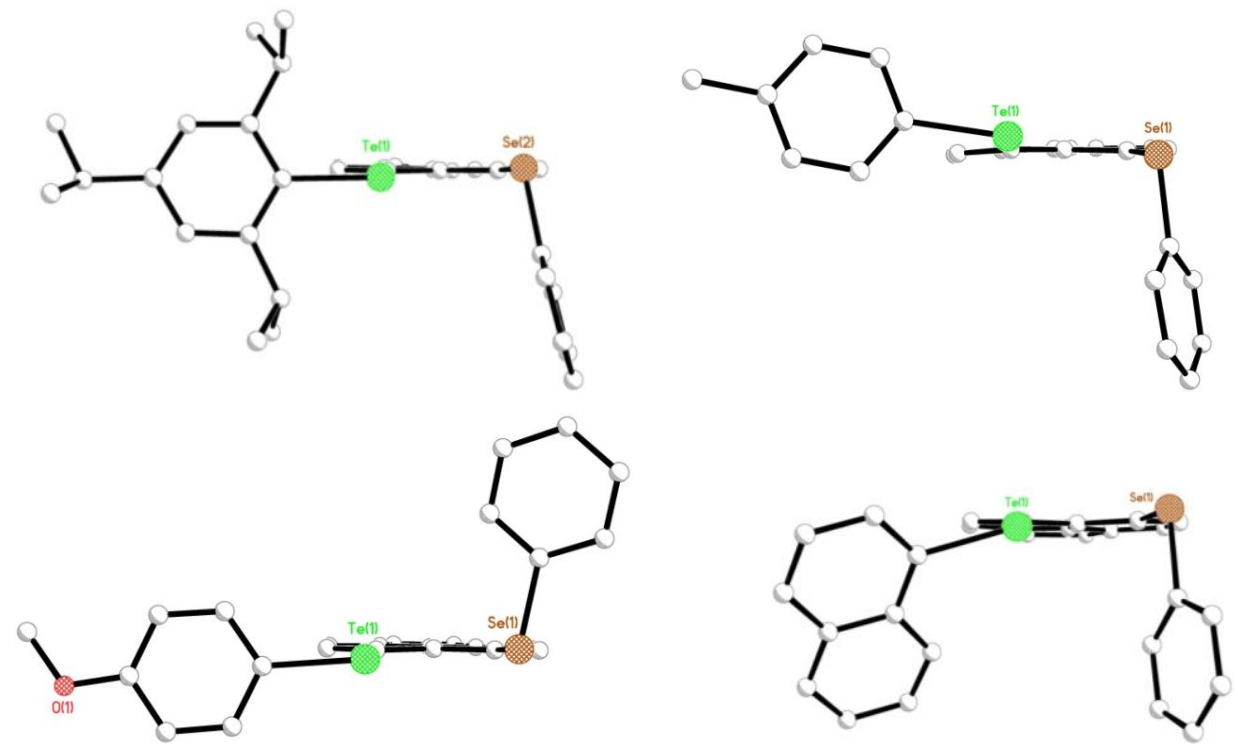

Fig. 7 The majority of compounds in this study adopt the BA type configuration, with minor differences between the structures resulting from rotation around the $\mathrm{E}_{-\mathrm{C}_{\mathrm{Ar}}}$ bonds: clockwise from top left: Te(Tip) 8 (B:pd; A:pl), Te(Tol) 3 (B:pd; A:np), Te(Nap) 9 (B:np; A:pl), Te(An-p) 4 (B:pd; A:pd); H 5 atoms omitted for clarity. The structures of $\mathbf{2 , 6}$ and 7, adopting the same structural conformation as $\mathbf{8}$, are omitted here put can be found in the ESI.

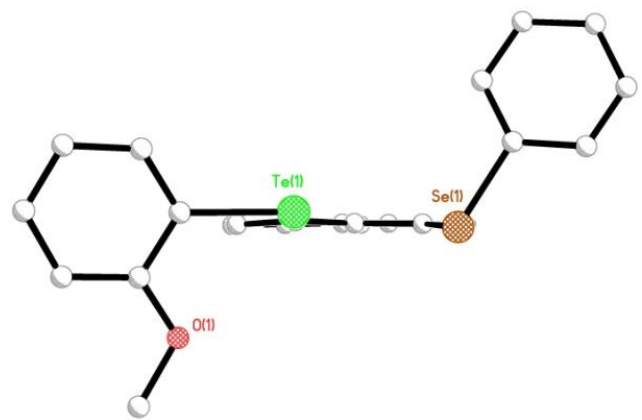

Fig. $8 \mathrm{Te}$ (An-o) 5 adopts an anomalous structure to the remaining members of the series, the $\mathrm{Se}(\mathrm{Ph})$ moiety aligning with a twist $(\mathbf{C})$ orientation (B:pd; C:np); H atoms omitted for clarity.

$10 \mathbf{n p}$ variations are observed for compounds 3-5.

The similarity of the structural configurations adopted by compounds 1-9 implies the steric bulk of the Te(aryl) moiety plays little part in determining the overall geometry of the molecule. This lack of dependence upon the form of the Te(aryl) 15 group is mirrored in the architecture of the acenaphthene fragment of each compound, with no apparent correlation between the steric bulk of the Te(aryl) functionality and thedegree of molecular distortion occurring within the organic framework. This is best highlighted by comparing the nonbonded 20 Te...Se peri-distances which are all within $0.08 \AA$, spanning a range from $3.2098(6) \AA$ in $8 \mathrm{Te}$ (Tip) to $3.2809(7) \AA$ in 7 $\mathrm{Te}(\mathrm{Mes})$. In plane distortion, measuring the divergence of the exocyclic $\mathrm{E}-\mathrm{C}_{\mathrm{Ar}}$ bonds within the acenaphthene plane, varies inconsistently throughout the series with splay angles (sum of the 25 bay region angles $-360^{\circ}$ ) ranging from $15.4^{\circ}-18.7^{\circ}$.

Interestingly, compounds substituted by the larger aryl moieties (8 Tip, 7 Mes, 9 Nap, 5 An- $o$, 4 An- $p$ ) display the greatest degree of planarity, experiencing only minor deformation of the organic framework (central C-C-C-C acenaphthene torsion 30 angles $0.1-2.5^{\circ}$ ) and with peri-atoms displaced to a maximum 0.3 $\AA$ from the mean plane. The remaining members of the series (1 $\mathrm{Ph}, 2$ Fp, 3 Tol, $6 \mathrm{Tp}$ ) display greater deformation, with minor buckling of the organic backbone (central torsion angles 1-4 ${ }^{\circ}$ ) combined with greater out-of-plane distortion (displacement from 35 the plane $0.3-0.4 \AA$ ).

\section{DFT Calculations}

In order to assess the extent of three-centre, four-electron type interactions occurring in the series, density functional theory (DFT/B3LYP) calculations were performed for the whole set of 40 compounds of this study. ${ }^{27}$ All nine structures optimised to a BA conformation with essentially perpendicular and in-plane alignment of the $\mathrm{SePh}$ and $\mathrm{TeY}$ moieties, respectively. In all cases, except for $\mathbf{5}$, the most stable conformer corresponded to the solid state structure. For $\mathbf{5}$, the energy span between the optimised 45 BA form and the observed BC variant is remarkably small. Freezing all non-hydrogens and only optimising the H-positions results in the $\mathrm{BC}$ structure lying $3.2 \mathrm{kcal} \mathrm{mol}^{-1}$ above the fully optimised minimum, however, relaxing all parameters except the two torsion angles $\mathrm{C} 10-\mathrm{C} 1-\mathrm{Te} 1-\mathrm{C}_{\mathrm{Y}}$ and $\mathrm{C} 10-\mathrm{C} 9-\mathrm{Se} 1-\mathrm{C}_{\mathrm{Ph}}$ (Table 503 ), affords a structure only $0.6 \mathrm{kcal} \mathrm{mol}^{-1}$ above the minimum. It thus costs precious little to move between conformations by rotation of the $\mathrm{E}(\operatorname{aryl})$ moieties, as previously observed in the $\operatorname{Nap}\left(\mathrm{TeMe}_{2}\right)$ model. $^{20}$

From structural analyses (peri-distances within $0.08 \AA$ ) and ${ }_{55}$ comparable SSCCs obtained in the ${ }^{77} \mathrm{Se}$ and ${ }^{125} \mathrm{Te}$ NMR spectra 


\section{Cite this: DOI: 10.1039/c0xx00000x}

www.rsc.org/xXXXXX

ARTICLE TYPE

Table 2 Computed properties of Acenap(TeAr)(SePh) derivatives (B3LYP level)

\begin{tabular}{|c|c|c|c|c|c|c|c|c|c|}
\hline & $1 \mathrm{Ph}$ & 2 Fp & 3 Tol & 4 An-P & 5 An-o & $6 \mathrm{Tp}$ & 7 Mes & 8 Tip & 9 Nap \\
\hline $\mathrm{d}(\mathrm{Te} \cdots \mathrm{Se}) \AA$ & $3.273^{a}$ & 3.274 & 3.282 & 3.282 & 3.273 & 3.285 & 3.287 & 3.292 & 3.279 \\
\hline$X$-ray & 3.248 & 3.218 & $3.229 / 3.202$ & 3.213 & $3.279 / 3.213$ & 3.233 & 3.281 & 3.210 & 3.233 \\
\hline WBI & 0.11 & 0.11 & 0.11 & 0.11 & 0.11 & 0.11 & 0.11 & 0.10 & 0.11 \\
\hline
\end{tabular}

Table 3 Computed and measured torsion angles for BA and BC conformers of 5

\begin{tabular}{llll}
\hline Level & C10-C1-Te1-C13 & C10-C9-Se1-C20 & Conformation \\
X-ray & -179.8 & -122.4 & BC \\
B3LYP & -168.6 & -100.9 & BA
\end{tabular}

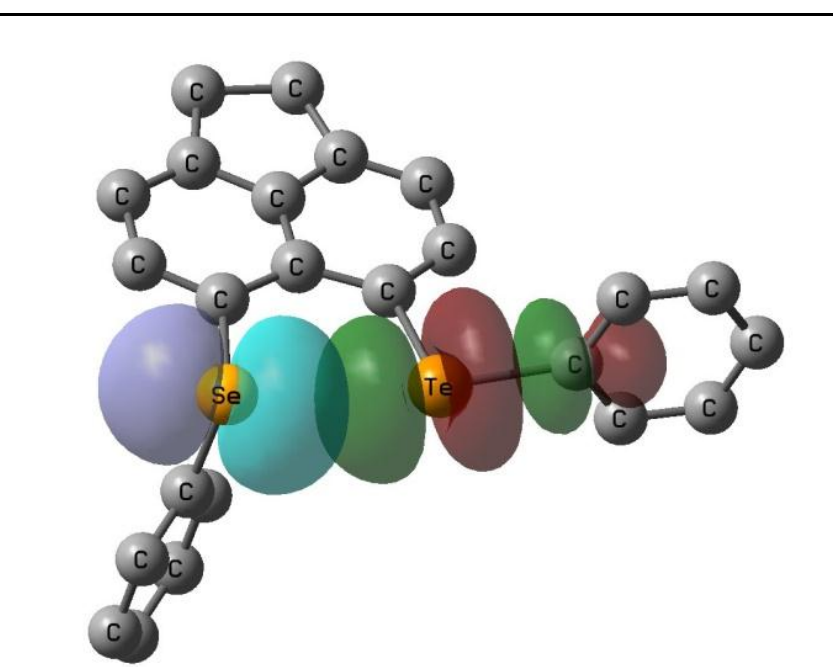

Fig. 9 Localised natural bond orbitals in 1 BA (B3LYP level): The lone pair on one Se can act as a weak donor into the $\sigma^{*}\left(\mathrm{Te}-\mathrm{C}_{\mathrm{Y}}\right)$ orbital on the other side of the peri-gap. Hydrogen atoms omitted for clarity.

10 of 1-9 $(J(\mathrm{Te}, \mathrm{Se})$ within $67 \mathrm{~Hz})$, the extent of covalent bonding between $\mathrm{Te}$ and $\mathrm{Se}$ is predicted to be consistent throughout the series. Indeed, similar $\mathrm{WBIs}^{22}$ are obtained in the region of 0.1 units, although this value is slightly lower than found in bistellurium species Acenap $(\mathrm{TePh})_{2}(0.14),{ }^{17}$ indicating a reduction 15 in multicenter bonding in the mixed systems. Nevertheless, a significant donor-acceptor interaction is encountered in the second-order perturbation analysis of the natural bond orbitals (NBOs) ${ }^{31}$ involving a p-type lone pair on Se and a $\sigma^{*}\left(\mathrm{Te}-\mathrm{C}_{\mathrm{Y}}\right)$ antibonding orbital. The primary NBOs are plotted for $\mathbf{1}(\mathrm{TePh})$

20 in Figure 9, where this donor-acceptor interaction is predicted to be worth $c a .42-45 \mathrm{~kJ} \mathrm{~mol}^{-1}$, again slightly smaller than in the ditelluride, where this interaction amounts to $c a .50 \mathrm{~kJ} \mathrm{~mol}^{-1}$.

\section{Experimental section}

All experiments were carried out under an oxygen- and moisture-
${ }_{25}$ free nitrogen atmosphere using standard Schlenk techniques and glassware. Reagents were obtained from commercial sources and used as received. Dry solvents were collected from a MBraun solvent system. Elemental analyses were performed by Stephen Boyer at the London Metropolitan University. Infra-red spectra 30 were recorded for solids as $\mathrm{KBr}$ discs and oils on $\mathrm{NaCl}$ plates in the range $4000-300 \mathrm{~cm}^{-1}$ on a Perkin-Elmer System 2000 Fourier transform spectrometer. ${ }^{1} \mathrm{H}$ and ${ }^{13} \mathrm{C}$ NMR spectra were recorded on a Bruker Avance $300 \mathrm{MHz}$ spectrometer with $\delta(\mathrm{H})$ and $\delta(\mathrm{C})$ referenced to external $\mathrm{Me}_{4} \mathrm{Si} .{ }^{77} \mathrm{Se}$ and ${ }^{125} \mathrm{Te}$ NMR spectra were 35 recorded on a Jeol GSX $270 \mathrm{MHz}$ spectrometer with $\delta(\mathrm{Se})$ and $\delta(\mathrm{Te})$ referenced to external $\mathrm{Me}_{2} \mathrm{Se}$ and $\mathrm{Me}_{2} \mathrm{Te}$ respectively, with a secondary reference for $\delta(\mathrm{Te})$ to diphenyl ditelluride $(\delta(\mathrm{Te})=$ 428 ppm). Assignments of ${ }^{13} \mathrm{C}$ and ${ }^{1} \mathrm{H}$ NMR spectra were made with the help of $\mathrm{H}-\mathrm{H}$ COSY and HSQC experiments. All 40 measurements were performed at $25{ }^{\circ} \mathrm{C}$. All values reported for NMR spectroscopy are in parts per million (ppm). Coupling constants $(J)$ are given in Hertz $(\mathrm{Hz})$. Electrospray Mass Spectrometry (ESMS) was performed by the University of St. Andrews Mass Spectrometry service on a Micromass LCT 45 orthogonal accelerator time of flight mass spectrometer. Acenaphthene precursor 5-bromo-6(phenylselenyl)acenaphthene was prepared following standard literature procedures. ${ }^{17} \mathrm{Bis}(4-$ fluorophenyl) ditelluride (FpTeTeFp), bis(4-methylphenyl) ditelluride (TolTeTeTol), bis(4-methoxyphenyl) ditelluride (An${ }_{50} p$ TeTeAn- $p$ ), bis(2-methoxyphenyl) ditelluride (An-oTeTeAn-o), bis(4-tertbutylphenyl) ditelluride (TpTeTeTp), bis(2,4,6trimethylphenyl) ditelluride (MesTeTeMes), bis(2,4,6triisopropanylphenyl) ditelluride (TipTeTeTip) and bis(1naphthyl) ditelluride (NapTeTeNap) were synthesised from the 55 respective aryl bromides following the procedure outlined by Ando and co-workers. ${ }^{32}$

\section{5-(4-fluorophenyltelluro)-6-(phenylselenyl)acenaphthene} [Acenap(TeFp)(SePh)] (2): To a solution of 5-bromo-660 (phenylselenyl)acenaphthene [Acenap $(\mathrm{Br})(\mathrm{SePh})](0.87 \mathrm{~g}, 2.25$ $\mathrm{mmol})$ in diethyl ether $(40 \mathrm{~mL})$ at $-78{ }^{\circ} \mathrm{C}$ was added dropwise a $2.5 \mathrm{M}$ solution of $n$-butyllithium in hexane $(0.9 \mathrm{~mL}, 2.25 \mathrm{mmol})$. The mixture was stirred at this temperature for $1 \mathrm{~h}$ after which a solution of bis(4-flurorophenyl) ditelluride [(FpTe $\left.)_{2}\right](1.00 \mathrm{~g}, 2.25$ $65 \mathrm{mmol})$ in diethyl ether $(80 \mathrm{~mL})$ was added dropwise to the mixture. The resulting mixture was stirred at $-78^{\circ} \mathrm{C}$ for a further $1 \mathrm{~h}$ and then allowed to warm to room temperature. The reaction mixture was then washed with $0.1 \mathrm{M}$ aqueous sodium hydroxide 
Cite this: DOI: $10.1039 / \mathrm{c} 0 \mathrm{xx} 00000 \mathrm{x}$

www.rsc.org/xxxxxx

ARTICLE TYPE

Table 4 Selected interatomic distances $[\AA]$ and angles $\left[^{\circ}\right]$ for compounds $\mathbf{2 - 5}$

\begin{tabular}{|c|c|c|c|c|}
\hline Compound & 2 & 3 & 4 & 5 \\
\hline Peri-atoms & $\mathrm{TeFp}, \mathrm{SePh}$ & TeTol, SePh & $\mathrm{TeAn}-p, \mathrm{SePh}$ & $\mathrm{TeAn}-o, \mathrm{SePh}$ \\
\hline \multicolumn{5}{|c|}{ Peri-region-distances } \\
\hline $\operatorname{Te}(1) \cdots \operatorname{Se}(1)$ & $3.2177(7)$ & $3.2289(8)[3.2021(8)]$ & $3.2132(15)$ & $3.2127(17)[3.2792(18)]$ \\
\hline$\% \Sigma \mathrm{r}_{\mathrm{vdW}}{ }^{a}$ & 81 & $82[81]$ & 81 & $81[83]$ \\
\hline \multicolumn{5}{|c|}{ Acenaphthene bond lengths } \\
\hline $\mathrm{C}(1)-\mathrm{C}(2)$ & $1.388(4)$ & $1.375(7)[1.389(7)]$ & $1.360(15)$ & $1.370(10)[1.390(13)]$ \\
\hline $\mathrm{C}(2)-\mathrm{C}(3)$ & $1.395(5)$ & $1.406(5)[1.406(5)]$ & $1.394(15)$ & $1.420(13)[1.430(14)]$ \\
\hline $\mathrm{C}(3)-\mathrm{C}(4)$ & $1.370(5)$ & $1.355(8)[1.352(7)]$ & $1.368(14)$ & $1.364(15)[1.362(15)]$ \\
\hline $\mathrm{C}(4)-\mathrm{C}(5)$ & $1.414(4)$ & $1.413(7)[1.417(7)]$ & $1.407(17)$ & $1.397(11)[1.371(12)]$ \\
\hline $\mathrm{C}(5)-\mathrm{C}(10)$ & $1.413(5)$ & $1.413(5)[1.410(5)]$ & $1.411(16)$ & $1.442(14)[1.436(12)]$ \\
\hline $\mathrm{C}(5)-\mathrm{C}(6)$ & $1.404(4)$ & $1.400(7)[1.398(7)]$ & $1.408(15)$ & $1.416(15)[1.416(16)]$ \\
\hline $\mathrm{C}(6)-\mathrm{C}(7)$ & $1.366(4)$ & $1.372(8)[1.366(8)]$ & $1.36(2)$ & $1.398(11)[1.373(15)]$ \\
\hline $\mathrm{C}(7)-\mathrm{C}(8)$ & $1.407(5)$ & $1.410(5)[1.415(5)]$ & $1.38(3)$ & $1.389(15)[1.394(14)]$ \\
\hline $\mathrm{C}(8)-\mathrm{C}(9)$ & $1.378(5)$ & $1.369(7)[1.377(7)]$ & $1.379(17)$ & $1.360(16)[1.363(16)]$ \\
\hline $\mathrm{C}(9)-\mathrm{C}(10)$ & $1.432(4)$ & $1.443(7)[1.433(7)]$ & $1.442(16)$ & $1.426(11)[1.428(13)]$ \\
\hline $\mathrm{C}(10)-\mathrm{C}(1)$ & $1.430(4)$ & $1.431(7)[1.432(7)]$ & $1.447(13)$ & $1.454(14)[1.442(15)]$ \\
\hline $\mathrm{C}(4)-\mathrm{C}(11)$ & $1.502(5)$ & $1.516(5)[1.511(5)]$ & $1.507(16)$ & $1.532(15)[1.522(15)]$ \\
\hline $\mathrm{C}(11)-\mathrm{C}(12)$ & $1.556(4)$ & $1.551(8)[1.550(8)]$ & $1.520(18)$ & $1.555(14)[1.542(16)]$ \\
\hline$C(12)-C(6)$ & $1.512(5)$ & $1.518(5)[1.520(5)]$ & $1.51(2)$ & $1.490(13)[1.528(13)]$ \\
\hline \multicolumn{5}{|c|}{ Peri-region bond angles } \\
\hline $\mathrm{Te}(1)-\mathrm{C}(1)-\mathrm{C}(10)$ & $123.24(19)$ & $124.1(3)[124.7(3)]$ & $122.6(8)$ & $123.5(5)[123.2(6)]$ \\
\hline $\mathrm{C}(1)-\mathrm{C}(10)-\mathrm{C}(9)$ & $130.1(3)$ & $130.7(3)[129.2(3)]$ & $130.3(10)$ & 131.1(9) [132.0(8)] \\
\hline $\operatorname{Se}(1)-C(9)-C(10)$ & 122.1(3) & $121.5(3)[122.0(3)]$ & $123.3(8)$ & $121.6(8)[121.1(7)]$ \\
\hline$\Sigma$ of bay angles & $375.44(19)$ & $376.3(5)[375.9(5)]$ & $376.3(15)$ & $376.2(13)[375.4(12)]$ \\
\hline Splay angle ${ }^{b}$ & 15.4 & $16.3[15.9]$ & 16.3 & $16.2[15.4]$ \\
\hline \multicolumn{5}{|c|}{ Out-of-plane displacement } \\
\hline $\mathrm{Te}(1)$ & $0.360(1)$ & $0.365(1)[-0.285(1)]$ & $-0.129(1)$ & $0.200(1)[0.305(1)]$ \\
\hline $\operatorname{Se}(1)$ & $-0.356(1)$ & $-0.086(1)[0.263(1)$ & $0.100(1)$ & $-0.071(1)[-0.395(1)]$ \\
\hline \multicolumn{5}{|c|}{ Central naphthalene ring torsion angles } \\
\hline $\mathrm{C}:(6)-(5)-(10)-(1)$ & 177.2(2) & $179.2(4)[-178.1(4)]$ & $-178.4(9)$ & $178.0(8)[176.1(7)]$ \\
\hline $\mathrm{C}:(4)-(5)-(10)-(9)$ & $175.7(2)$ & $176.8(4)[-176.8(4)]$ & $-179.9(8)$ & $178.4(8)[176.2(8)]$ \\
\hline
\end{tabular}

${ }^{a}$ van der Waals radii used for calculations: $\mathrm{r}_{\mathrm{vdw}}(\mathrm{Se}) 1.90 \AA \mathrm{r}_{\mathrm{vdW}}(\mathrm{Te}) 2.06 \AA{ }^{30 \mathrm{~b}}$ Splay angle: $\Sigma$ of the three bay region angles -360 .

$(3 \times 100 \mathrm{~mL})$, the organic layer dried with magnesium sulfate and concentrated under reduced pressure. The residual red/orange 5 solid was triturated with hexane to afford the purified target compound as a pale yellow solid. An analytically pure sample was obtained from recrystallisation by diffusion of hexane into a saturated solution of the compound in dichloromethane $(0.51 \mathrm{~g}$, 43\%); mp 126-128 ${ }^{\circ} \mathrm{C}$; elemental analysis (Found: C, 54.3; H, 10 3.2. Calc. for $\mathrm{C}_{24} \mathrm{H}_{17} \mathrm{FSeTe}$ C, 54.3; H, 3.2\%); ${ }^{1} \mathrm{H}$ NMR (300 $\left.\mathrm{MHz}, \mathrm{CDCl}_{3}, 25^{\circ} \mathrm{C}, \mathrm{Me}_{4} \mathrm{Si}\right) \delta=7.85\left(1 \mathrm{H}, \mathrm{d},{ }^{3} J_{\mathrm{HH}} 7.2\right.$, Acenap 4H), $7.75\left(2 \mathrm{H}, \mathrm{dd},{ }^{3} J_{\mathrm{HH}} 8.7,{ }^{3} J_{\mathrm{HF}} 6.0, \mathrm{Te} F p 12,16-\mathrm{H}\right), 7.17-7.10$ (4 H, m, Acenap 3,7-H, SePh 18,22-H), 7.08-7.03 (3 H, m, SePh 19,20,21-H), 6.92-6.84 (3 H, m, Acenap 8-H, TeFp 13,15-H), 15 3.29-3.21 (4 H, m, $\left.2 \times \mathrm{CH}_{2}\right) ;{ }^{19} \mathrm{~F}\left\{{ }^{1} \mathrm{H}\right\}$ NMR (282 MHz, $\mathrm{CDCl}_{3}$, $\left.25{ }^{\circ} \mathrm{C}, \mathrm{CFCl}_{3}\right) \delta=-112.7(\mathrm{~s}) ;{ }^{77} \mathrm{Se} \mathrm{NMR}\left(51.5 \mathrm{MHz}, \mathrm{CDCl}_{3}, 25\right.$ $\left.{ }^{\circ} \mathrm{C}, \mathrm{PhSeSePh}\right): \delta=340$ (s, $\left.J_{\mathrm{SeTe}} 726\right) ;{ }^{125} \mathrm{Te} \mathrm{NMR}(85.2 \mathrm{MHz}$, $\left.\mathrm{CDCl}_{3}, 25^{\circ} \mathrm{C}, \mathrm{PhTeTePh}\right): \delta=653\left(\mathrm{~s}, J_{\mathrm{TeSe}} 726\right) ; \mathrm{MS}\left(\mathrm{ES}^{+}\right): \mathrm{m} / \mathrm{z}$ $548.95(100 \%, \mathrm{M}+\mathrm{OH}), 562.97(73, \mathrm{M}+\mathrm{OMe})$.

20

5-(4-methylphenyltelluro)-6-(phenylselenyl)acenaphthene [Acenap(TeTol)(SePh)] (3): Experimental as for compound 2 but with [Acenap $(\mathrm{Br})(\mathrm{SePh})](0.80 \mathrm{~g}, 2.06 \mathrm{mmol}), 2.5 \mathrm{M} n$ butyllithium $(0.9 \mathrm{~mL}, 2.25 \mathrm{mmol})$ and bis(4-methylphenyl) ${ }_{25}$ ditelluride [(TolTe $\left.)_{2}\right](0.87 \mathrm{~g}, 1.99 \mathrm{mmol})$ to afford the target compound as a pale yellow solid. An analytically pure sample was obtained from recrystallisation by diffusion of hexane into a saturated solution of the compound in dichloromethane $(0.46 \mathrm{~g}$, 


\section{Cite this: DOI: $10.1039 / \mathrm{c0xx} 00000 x$}

www.rsc.org/xxxxxx

ARTICLE TYPE

Table 5 Selected interatomic distances $[\AA]$ and angles $\left[{ }^{\circ}\right]$ for compounds 6-9.

\begin{tabular}{|c|c|c|c|c|}
\hline Compound & 6 & 7 & 8 & 9 \\
\hline Peri-atoms & $\mathrm{TeTp}, \mathrm{SePh}$ & TeMes, SePh & TeTip, SePh & TeNap, SePh \\
\hline \multicolumn{5}{|c|}{ Peri-region-distances } \\
\hline $\operatorname{Te}(1) \cdots \operatorname{Se}(1)$ & $3.2330(6)$ & $3.2809(7)$ & $3.2098(6)$ & $3.2586(7)$ \\
\hline$\% \Sigma \mathrm{r}_{\mathrm{vdW}}{ }^{a}$ & 82 & 83 & 81 & 82 \\
\hline \multicolumn{5}{|c|}{ Acenaphthene bond lengths } \\
\hline$C(1)-C(2)$ & $1.385(5)$ & $1.390(5)$ & $1.382(7)$ & $1.379(5)$ \\
\hline $\mathrm{C}(2)-\mathrm{C}(3)$ & $1.410(5)$ & $1.401(5)$ & $1.408(8)$ & $1.411(5)$ \\
\hline $\mathrm{C}(3)-\mathrm{C}(4)$ & $1.363(5)$ & $1.358(4)$ & $1.358(8)$ & $1.358(5)$ \\
\hline $\mathrm{C}(4)-\mathrm{C}(5)$ & $1.404(5)$ & $1.411(5)$ & $1.409(7)$ & $1.403(5)$ \\
\hline $\mathrm{C}(5)-\mathrm{C}(10)$ & $1.415(5)$ & $1.416(4)$ & $1.419(8)$ & $1.415(5)$ \\
\hline $\mathrm{C}(5)-\mathrm{C}(6)$ & $1.416(4)$ & $1.419(4)$ & $1.412(8)$ & $1.416(5)$ \\
\hline $\mathrm{C}(6)-\mathrm{C}(7)$ & $1.363(5)$ & $1.359(5)$ & $1.356(8)$ & $1.356(6)$ \\
\hline $\mathrm{C}(7)-\mathrm{C}(8)$ & $1.399(5)$ & $1.409(5)$ & $1.417(9)$ & $1.406(6)$ \\
\hline $\mathrm{C}(8)-\mathrm{C}(9)$ & $1.379(5)$ & $1.381(4)$ & $1.378(8)$ & $1.390(5)$ \\
\hline$C(9)-C(10)$ & $1.423(5)$ & $1.440(4)$ & $1.428(7)$ & $1.431(5)$ \\
\hline $\mathrm{C}(10)-\mathrm{C}(1)$ & $1.430(4)$ & $1.430(4)$ & $1.438(7)$ & $1.437(4)$ \\
\hline$C(4)-C(11)$ & $1.512(5)$ & $1.506(5)$ & $1.513(9)$ & $1.509(5)$ \\
\hline $\mathrm{C}(11)-\mathrm{C}(12)$ & $1.537(5)$ & $1.543(5)$ & $1.536(8)$ & $1.539(5)$ \\
\hline $\mathrm{C}(12)-\mathrm{C}(6)$ & $1.509(5)$ & $1.509(5)$ & $1.513(8)$ & $1.511(6)$ \\
\hline \multicolumn{5}{|c|}{ Peri-region bond angles } \\
\hline $\mathrm{Te}(1)-\mathrm{C}(1)-\mathrm{C}(10)$ & $123.4(3)$ & $124.5(3)$ & $124.0(4)$ & $123.8(3)$ \\
\hline $\mathrm{C}(1)-\mathrm{C}(10)-\mathrm{C}(9)$ & $130.0(3)$ & $130.4(3)$ & $130.5(5)$ & $130.4(3)$ \\
\hline $\mathrm{Se}(1)-\mathrm{C}(9)-\mathrm{C}(10)$ & $123.1(2)$ & $123.8(2)$ & $122.3(4)$ & $123.5(3)$ \\
\hline$\Sigma$ of bay angles & $376.5(5)$ & $378.7(5)$ & $376.8(7)$ & $377.7(5)$ \\
\hline Splay angle ${ }^{b}$ & 16.5 & 18.7 & 16.8 & 17.7 \\
\hline \multicolumn{5}{|c|}{ Out-of-plane displacement } \\
\hline $\mathrm{Te}(1)$ & $0.332(1)$ & $-0.058(1)$ & $-0.126(1)$ & $-0.319(1)$ \\
\hline $\operatorname{Se}(1)$ & $-0.294(1)$ & $-0.220(1)$ & $0.084(1)$ & $0.086(1)$ \\
\hline \multicolumn{5}{|c|}{ Central naphthalene ring torsion angles } \\
\hline$C:(6)-(5)-(10)-(1)$ & $179.2(3)$ & 179.7(2) & $-178.9(4)$ & $-179.0(3)$ \\
\hline C:(4)-(5)-(10)-(9) & $176.7(3)$ & $178.7(2)$ & $-178.0(4)$ & $-177.5(3)$ \\
\hline
\end{tabular}

${ }^{a}$ van der Waals radii used for calculations: $\mathrm{r}_{\mathrm{vdW}}(\mathrm{Se}) 1.90 \AA \mathrm{r}_{\mathrm{vdw}}(\mathrm{Te}) 2.06 \AA{ }^{30 \mathrm{~b}}$ Splay angle: $\Sigma$ of the three bay region angles -360 .

42\%); mp 145-147 ${ }^{\circ} \mathrm{C}$; elemental analysis (Found: C, 56.9; H, 3.9. Calc. for $\mathrm{C}_{25} \mathrm{H}_{20} \mathrm{SeTe}$ C, 57.0; H, 3.8\%); ${ }^{1} \mathrm{H}$ NMR $(300$ $\left.{ }_{5} \mathrm{MHz}, \mathrm{CDCl}_{3}, 25^{\circ} \mathrm{C}, \mathrm{Me}_{4} \mathrm{Si}\right) \delta=7.99\left(1 \mathrm{H}, \mathrm{d},{ }^{3} J_{\mathrm{HH}} 8.0\right.$, Acenap 4$\mathrm{H}), 7.84\left(2 \mathrm{H}, \mathrm{d},{ }^{3} J_{\mathrm{HH}} 7.9\right.$, TeTol 12,16-H), $7.36\left(1 \mathrm{H}, \mathrm{d},{ }^{3} J_{\mathrm{HH}} 7.5\right.$, Acenap 7-H), 7.32-7.15 (8 H, m, Acenap 3-H, TeTol 13,15-H, $\mathrm{SePh} 19,20,21,22,23-\mathrm{H}), 7.00$ (1 H, d, ${ }^{3} J_{\mathrm{HH}} 7.5$, Acenap 8-H), 3.44-3.32 (4 H, m, $\left.2 \times \mathrm{CH}_{2}\right), 2.44\left(3 \mathrm{H}, \mathrm{s}, \mathrm{CH}_{3}\right)$; ${ }^{77} \mathrm{Se} \mathrm{NMR}(51.5$ $\left.{ }_{10} \mathrm{MHz}, \mathrm{CDCl}_{3}, 25{ }^{\circ} \mathrm{C}, \mathrm{PhSeSePh}\right): \delta=342$ (s, $\left.J_{\mathrm{SeTe}} 723\right) ;{ }^{125} \mathrm{Te}$ NMR (85.2 MHz, $\left.\mathrm{CDCl}_{3}, 25^{\circ} \mathrm{C}, \mathrm{PhTeTePh}\right): \delta=649$ (s, $J_{\text {TeSe }}$ 723); $\mathrm{MS}\left(\mathrm{ES}^{+}\right): \mathrm{m} / z, 559.09(100 \%, \mathrm{M}+\mathrm{OMe})$.

5-(4-methoxyphenylltelluro)-6-(phenylselenyl)acenaphthene 15 [Acenap(TeAn-p)(SePh)] (4): Experimental as for compound 2 but with [Acenap(Br)(SePh)] $(0.87 \mathrm{~g}, 2.25 \mathrm{mmol}), 2.5 \mathrm{M} n$ butyllithium $(0.9 \mathrm{~mL}, 2.25 \mathrm{mmol})$ and bis(4-methoxyphenyl) ditelluride [(Ani- $p$ Te $\left.)_{2}\right](1.06 \mathrm{~g}, 2.25 \mathrm{mmol})$ to afford the target compound as a cream solid. An analytically pure sample was 20 obtained from recrystallisation by diffusion of hexane into a saturated solution of the compound in dichloromethane $(0.84 \mathrm{~g}$, 69\%); mp 164-165 ${ }^{\circ} \mathrm{C}$; elemental analysis (Found: C, 55.1; H, 3.7. Calc. for $\left.\mathrm{C}_{25} \mathrm{H}_{20} \mathrm{OSeTe}: \mathrm{C}, 55.3 ; \mathrm{H}, 3.7 \%\right)$. ${ }^{1} \mathrm{H}$ NMR (300 $\left.\mathrm{MHz}, \mathrm{CDCl}_{3}, 25^{\circ} \mathrm{C}, \mathrm{Me}_{4} \mathrm{Si}\right) \delta=8.00\left(1 \mathrm{H}, \mathrm{d},{ }^{3} J_{\mathrm{HH}} 7.1\right.$, Acenap 4$\left.{ }_{25} \mathrm{H}\right), 7.87\left(2 \mathrm{H}, \mathrm{d},{ }^{3} J_{\mathrm{HH}} 8.6\right.$, TeAn-p 12,16-H), 7.35-7.30 (3 H, m, Acenap 7-H, SePh 19,23-H), 7.26 (1 H, d, ${ }^{3} J_{\mathrm{HH}}$ 7.1, Acenap 3-H), 7.24-7.19 (3 H, m, SePh 20,21,22-H), 7.02 (1 H, d, ${ }^{3} J_{\mathrm{HH}} 7.4$, Acenap 8-H), $6.91\left(2 \mathrm{H}, \mathrm{d},{ }^{3} J_{\mathrm{HH}} 8.6\right.$, TeAn-p 13,15-H), $3.88(3 \mathrm{H}$, 


\section{Cite this: DOI: $10.1039 / \mathrm{c0xx00000x}$}

www.rsc.org/xxxxxx

ARTICLE TYPE

Table 6 Torsion angles $\left[{ }^{\circ}\right]$ categorizing the acenaphthene and aryl ring conformations in compounds 1-9.

\begin{tabular}{|c|c|c|c|c|}
\hline \multirow{2}{*}{$\begin{array}{l}\text { Compound } \\
\text { Torsion angle }\end{array}$} & \multicolumn{2}{|c|}{ Acenaphthene ring conformations } & \multicolumn{2}{|l|}{ Aryl ring conformations } \\
\hline & C10-C1-Te1-C ${ }_{R}$ & C10-C9-Se1-C $C_{P h}$ & C1-Te1-C13-C14 & C9-Se1-C19-C20 \\
\hline \multirow[t]{2}{*}{1} & $\theta_{1}-168.1(8)$ & $\theta_{2} 101.3(9)$ & $\gamma_{1} 83.6(7)$ & $\gamma_{2}-20.8(8)$ \\
\hline & Acenap $_{1}{ }^{a}$ : equatorial: type $\mathbf{B}$ & $\operatorname{Acenap}_{2}{ }^{b}: \operatorname{axial}^{e}:$ type A & $\mathrm{Ar}_{1}^{c}:$ axial: pd & $\mathrm{Ph}_{1}^{d}$ : equatorial: pl \\
\hline \multirow[t]{2}{*}{2} & $\theta_{1}-166.65(18)$ & $\theta_{2} 82.25(17)$ & $\gamma_{1}-99.3(3)$ & $\gamma_{2}-166.11(16)$ \\
\hline & Acenap $_{1}$ : equatorial: type $\mathbf{B}$ & Acenap $_{2}$ : axial: type $\mathbf{A}$ & $\mathrm{Ar}_{1}:$ axial: pd & $\mathrm{Ph}_{1}$ : equatorial: pl \\
\hline \multirow[t]{2}{*}{3} & $\theta_{1} 167.6(3)[-168.7(4)]$ & $\theta_{2} 94.4(3)[-86.6(4)]$ & $\gamma_{1} 95.5(3)[-114.0(3)]$ & $\gamma_{2}-142.2(4)[138.9(4)]$ \\
\hline & Acenapyl $_{1}$ : equatorial: type B & Acenap $_{2}$ : axial: type $\mathbf{A}$ & $\mathrm{Ar}_{1}:$ axial: pd [twist: $\mathbf{n p ]}$ & $\mathrm{Ph}_{1}$ : twist: $\mathbf{n p}$ [twist: $\mathbf{n p}$ ] \\
\hline \multirow[t]{2}{*}{4} & $\theta_{1}-174.8(6)$ & $\theta_{2}-99.3(8)$ & $\gamma_{1} 98.5(6)$ & $\gamma_{2}-109.3(7)$ \\
\hline & Acenap $_{1}$ : equatorial: type B & Acenap $_{2}$ : axial: type $\mathbf{A}$ & $\mathrm{Ar}_{1}:$ axial: pd & $\mathrm{Ph}_{1}$ : axial: pd \\
\hline \multirow[t]{2}{*}{5} & $\theta_{1}-179.8(6)[162.4(6)]$ & $\theta_{2}-122.4(7)[-123.4(6)]$ & $\gamma_{1} 78.4(7)[90.0(6)]$ & $\gamma_{2} 59.9(8)[81.9(7)]$ \\
\hline & Acenap $_{1}$ : equatorial: type $\mathbf{B}$ & Acenap $_{2}:$ twist: $^{g}$ type $\mathbf{C}$ & $\mathrm{Ar}_{1}:$ axial: pd & $\mathrm{Ph}_{1}$ : twist: $\mathbf{n p}$ [axial: pd] \\
\hline \multirow[t]{2}{*}{6} & $\theta_{1} 167.3(3)$ & $\theta_{2} 85.9(3)$ & $\gamma_{1} 97.8(3)$ & $\gamma_{2}-178.23(19)$ \\
\hline & Acenap $_{1}$ : equatorial: type $\mathbf{B}$ & Acenap $_{2}$ : axial: type $\mathbf{A}$ & $\mathrm{Ar}_{1}:$ axial: pd & $\mathrm{Ph}_{1}$ : equatorial: pl \\
\hline \multirow[t]{2}{*}{7} & $\theta_{1} 161.30(17)$ & $\theta_{2}-87.93(19)$ & $\gamma_{1}-70.45(18)$ & $\gamma_{2}-170.31(18)$ \\
\hline & Acenap $_{1}$ : equatorial: type $\mathbf{B}$ & Acenap $_{2}$ : axial: type $\mathbf{A}$ & $\mathrm{Ar}_{1}:$ axial: pd & $\mathrm{Ph}_{1}$ : equatorial: pl \\
\hline \multirow[t]{2}{*}{8} & $\theta_{1}-177.7(3)$ & $\theta_{2} 99.0(3)$ & $\gamma_{1} 106.7(3)$ & $\gamma_{2}-160.8(3)$ \\
\hline & Acenap $_{1}$ : equatorial: type $\mathbf{B}$ & Acenap $_{2}$ : axial: type A & $\mathrm{Ar}_{1}:$ axial: pd & $\mathrm{Ph}_{1}$ : equatorial: pl \\
\hline \multirow[t]{2}{*}{9} & $\theta_{1}-161.2(2)$ & $\theta_{2} 89.9(3)$ & $\gamma_{1}-125.8(2)$ & $\gamma_{2}-9.6(3)$ \\
\hline & Acenap $_{1}$ : equatorial: type $\mathbf{B}$ & Acenap $_{2}$ : axial: type $\mathbf{A}$ & $\mathrm{Ar}_{1}$ : twist: $\mathbf{n p}$ & $\mathrm{Ph}_{1}$ : equatorial: pl \\
\hline
\end{tabular}

${ }^{a}$ Acenap 1 : acenaphthene ring Te(1); ${ }^{b}$ Acenap 2 : acenaphthene ring $\mathrm{Se}(1) ;{ }^{c} \mathbf{A r} \mathbf{r}_{1}$ : Te(1) aryl ring; ${ }^{d} \mathbf{P h}_{\mathbf{1}}$ : $\mathrm{Se}(1)$ phenyl ring; ${ }^{e}$ axial: perpendicular to C(ar)-E$\mathrm{C}(\mathrm{ar})$ plane; ${ }^{f}$ equatorial: coplanar with C(ar)-E-C(ar) plane; ${ }^{g}$ twist: intermediate between axial and equatorial.

s, $\left.\mathrm{OCH}_{3}\right), 3.41-3.34$ (4 H, m, Acenap 9,10-H); ${ }^{77} \mathrm{Se} \mathrm{NMR} \mathrm{(51.5}$ $\left.{ }_{5} \mathrm{MHz}, \mathrm{CDCl}_{3}, 25{ }^{\circ} \mathrm{C}, \mathrm{PhSeSePh}\right): \delta=342$ (s, $\left.J_{\mathrm{SeTe}} 722\right) ;{ }^{125} \mathrm{Te}$ NMR (85.2 MHz, $\left.\mathrm{CDCl}_{3}, 25^{\circ} \mathrm{C}, \mathrm{PhTeTePh}\right): \delta=639$ (s, $J_{\text {TeSe }}$ 722); $\mathrm{MS}\left(\mathrm{ES}^{+}\right): m / z 574.99(100 \%, \mathrm{M}+\mathrm{OMe}), 543.97\left(43, \mathrm{M}^{+}\right)$.

5-(2-methoxyphenylltelluro)-6-(phenylselenyl)acenaphthene

10 [Acenap(TeAn-o)(SePh)] (5): Experimental as for compound 2 but with [Acenap(Br)(SePh)] $(0.87 \mathrm{~g}, 2.25 \mathrm{mmol}), 2.5 \mathrm{M} \mathrm{n}$ butyllithium $(0.9 \mathrm{~mL}, 2.25 \mathrm{mmol})$ and bis(2-methoxyphenyl) ditelluride $\left[(\mathrm{An}-\mathrm{oTe})_{2}\right](1.06 \mathrm{~g}, 2.25 \mathrm{mmol})$ to afford the target compound as a light brown solid. An analytically pure sample

15 was obtained from recrystallisation by diffusion of hexane into a saturated solution of the compound in dichloromethane $(0.82 \mathrm{~g}$, 67\%); mp 133-137 ${ }^{\circ} \mathrm{C}$; elemental analysis (Found: C, 55.3; H, 3.8. Calc. $\mathrm{C}_{25} \mathrm{H}_{20} \mathrm{OSeTe}$ C, 55.3; H, 3.7\%); ${ }^{1} \mathrm{H}$ NMR $(300 \mathrm{MHz}$, $\left.\mathrm{CDCl}_{3}, 25{ }^{\circ} \mathrm{C}, \mathrm{Me}_{4} \mathrm{Si}\right) \delta=7.93\left(1 \mathrm{H}, \mathrm{d},{ }^{3} \mathrm{~J}_{\mathrm{HH}} 7.2\right.$, Acenap 4-H), $207.83\left(1 \mathrm{H}, \mathrm{dd},{ }^{3} J_{\mathrm{HH}} 7.4,{ }^{4} J_{\mathrm{HH}} 1.6\right.$, TeAn-o 16-H), $7.49(1 \mathrm{H}, \mathrm{d}$, ${ }^{3} J_{\mathrm{HH}}$ 7.4, Acenap 7-H), 7.46-7.41 (1 H, m, TeAn-o 14-H), 7.387.34 (2 H, m, SePh 19,23-H), 7.25-7.19 (4 H, m, Acenap 3-H, $\mathrm{SePh} 3,20,21,22-\mathrm{H}), 7.04$ (1 H, d, ${ }^{3} J_{\mathrm{HH}}$ 7.4, Acenap 8-H), 7.00 (1 $\mathrm{H}, \mathrm{d},{ }^{3} J_{\mathrm{HH}}$ 8.2, TeAn-o 13-H), 6.94-6.89 (1 H, m, TeAn-o 15-H), $253.83\left(3 \mathrm{H}, \mathrm{s}, \mathrm{OCH}_{3}\right), 3.38\left(4 \mathrm{H}, \mathrm{m}, 2 \mathrm{x} \mathrm{CH}_{2}\right) ;{ }^{77} \mathrm{Se} \mathrm{NMR}(51.5$ $\left.\mathrm{MHz}, \mathrm{CDCl}_{3}, 25{ }^{\circ} \mathrm{C}, \mathrm{PhSeSePh}\right): \delta=347$ (s, $\left.J_{\mathrm{SeTe}} 748\right) ;{ }^{125} \mathrm{Te}$ NMR (85.2 MHz, $\left.\mathrm{CDCl}_{3}, 25^{\circ} \mathrm{C}, \mathrm{PhTeTePh}\right): \delta=544$ (s, $J_{\text {TeSe }}$ 748); $\mathrm{MS}\left(\mathrm{ES}^{+}\right): \mathrm{m} / z 574.99(100 \%, \mathrm{M}+\mathrm{OMe})$.
${ }_{30}$ 5-(4-tertbutylphenyltelluro)-6-(phenylselenyl)acenaphthene [Acenap(TeTp)(SePh)] (6): Experimental as for compound 2 but with [Acenap $(\mathrm{Br})(\mathrm{SePh})] \quad(0.8 \mathrm{~g}, 2.06 \mathrm{mmol}), 2.5 \mathrm{M} n$ butyllithium $(0.9 \mathrm{~mL}, 2.25 \mathrm{mmol})$ and bis(4-tertbutylphenyl) ditelluride $\left[(\mathrm{TpTe})_{2}\right](1.07 \mathrm{~g}, 2.06 \mathrm{mmol})$ to afford the target 35 compound as a brown solid. An analytically pure sample was obtained from recrystallisation by diffusion of hexane into a saturated solution of the compound in dichloromethane $(0.27 \mathrm{~g}$, 23\%); mp 149-141 ${ }^{\circ} \mathrm{C}$; elemental analysis (Found: C, 59.0; H, 4.5. Calc. for $\mathrm{C}_{28} \mathrm{H}_{26}$ SeTe: C, 59.1; $\left.\mathrm{H}, 4.6 \%\right) ;{ }^{1} \mathrm{H}$ NMR (300 $\left.{ }_{40} \mathrm{MHz}, \mathrm{CDCl}_{3}, 25^{\circ} \mathrm{C}, \mathrm{Me}_{4} \mathrm{Si}\right) \delta=7.99\left(1 \mathrm{H}, \mathrm{d},{ }^{3} J_{\mathrm{HH}} 7.2\right.$, Acenap 4$\mathrm{H}), 7.87\left(2 \mathrm{H}, \mathrm{d},{ }^{3} J_{\mathrm{HH}} 8.3, \mathrm{Te} T p 12,16-\mathrm{H}\right), 7.41\left(1 \mathrm{H}, \mathrm{d},{ }^{3} J_{\mathrm{HH}} 7.5\right.$, Acenap 7-H), $7.38\left(2 \mathrm{H}, \mathrm{d},{ }^{3} J_{\mathrm{HH}} 8.3\right.$, TeTp 13,15-H), 7.32-7.29 (2 $\mathrm{H}, \mathrm{m}, \mathrm{Se} P h$ 21,25-H), 7.26 (1 H, d, ${ }^{3} J_{\mathrm{HH}}$ 7.3, Acenap 3-H), 7.237.17 (3 H, m, SePh 22,23,24-H), 7.03 (1 H, d, ${ }^{3} J_{\mathrm{HH}}$ 7.4, Acenap ${ }_{45}$ 8-H), 3.44-3.34 (4 H, m, $\left.2 \times \mathrm{CH}_{2}\right), 1.40\left(9 \mathrm{H}, \mathrm{s}, 3 \times \mathrm{CH}_{3}\right) ;{ }^{77} \mathrm{Se}$ NMR (51.5 MHz, $\left.\mathrm{CDCl}_{3}, 25{ }^{\circ} \mathrm{C}, \mathrm{PhSeSePh}\right): \delta=343\left(\mathrm{~s}, J_{\mathrm{SeTe}}\right.$ 723); ${ }^{125} \mathrm{Te} \mathrm{NMR}\left(85.2 \mathrm{MHz}, \mathrm{CDCl}_{3}, 25^{\circ} \mathrm{C}, \mathrm{PhTeTePh}\right): \delta=643$ (s, $J_{\mathrm{TeSe}}$ 723); MS (ES $\left.{ }^{+}\right): m / z, 601.04(100 \%, \mathrm{M}+\mathrm{OMe})$.

${ }_{50}$ 5-(2,4,6-trimethylphenyltelluro)-6-

(phenylselenyl)acenaphthene [Acenap(TeMes)(SePh)] (7): Experimental as for compound $\mathbf{2}$ but with [Acenap $(\mathrm{Br})(\mathrm{SePh})$ ] (1.0 g, $2.63 \mathrm{mmol}), 2.5 \mathrm{M} n$-butyllithium (1.1 mL, $2.65 \mathrm{mmol})$ and bis(2,4,6-trimethylphenyl) ditelluride [(MesTe $\left.)_{2}\right](1.31 \mathrm{~g}$, $552.63 \mathrm{mmol}$ ) to afford the target compound as a cream solid. An 
analytically pure sample was obtained from recrystallisation by diffusion of hexane into a saturated solution of the compound in dichloromethane $(0.30 \mathrm{~g}, 21 \%)$; $\mathrm{mp} 145-147{ }^{\circ} \mathrm{C}$; elemental analysis (Found: $\mathrm{C}, 58.55$; $\mathrm{H}, 4.3$. Calc. for $\mathrm{C}_{27} \mathrm{H}_{24} \mathrm{SeTe}$ : C, 58.4; $\left.{ }_{5} \mathrm{H}, 4.4 \%\right) ;{ }^{1} \mathrm{H} \mathrm{NMR}\left(300 \mathrm{MHz}, \mathrm{CDCl}_{3}, 25{ }^{\circ} \mathrm{C}, \mathrm{Me}_{4} \mathrm{Si}\right) \delta=7.89(1$ $\mathrm{H}, \mathrm{d},{ }^{3} J_{\mathrm{HH}}$ 7.1, Acenap 4-H), 7.23-7.20 (2 H, m, SePh 21,25-H), $7.14\left(1 \mathrm{H}, \mathrm{d},{ }^{3} J_{\mathrm{HH}} 7.1\right.$, Acenap 3-H), 7.12-7.06 (3 H, m, SePh 22,23,24-H), 7.04 (1 H, d, ${ }^{3} J_{\mathrm{HH}} 7.4$, Acenap 7-H), $6.94(2 \mathrm{H}, \mathrm{s}$, TeMes 13,15-H), 6.85 (1 H, d, ${ }^{3} J_{\mathrm{HH}}$ 7.4, Acenap 8-H), 3.30-3.23 $10\left(4 \mathrm{H}, \mathrm{m}, 2 \times \mathrm{CH}_{2}\right), 2.42$ (6 H, s, TeMes 17,19-H), $2.25(3 \mathrm{H}, \mathrm{s}$, TeMes $\left.18-\mathrm{H}) ;{ }^{77} \mathrm{Se} \mathrm{NMR} \mathrm{(51.5} \mathrm{MHz,} \mathrm{CDCl}_{3}, 25^{\circ} \mathrm{C}, \mathrm{PhSeSePh}\right)$ : $\delta=345$ (s, $\left.J_{\mathrm{SeTe}} 711\right) ;{ }^{125} \mathrm{Te} \mathrm{NMR}\left(85.2 \mathrm{MHz}, \mathrm{CDCl}_{3}, 25{ }^{\circ} \mathrm{C}\right.$, PhTeTePh): $\delta=428$ (s, $\left.J_{\text {TeSe }} 711\right)$; MS (ES $\left.{ }^{+}\right): m / z 587.12(100 \%$, $\mathrm{M}+\mathrm{OMe})$.

15

5-(2,4,6-triisopropylphenylltelluro)-6-

(phenylselenyl)acenaphthene [Acenap(TeTip)(SePh)] (8):

Experimental as for compound $\mathbf{2}$ but with [Acenap $(\mathrm{Br})(\mathrm{SePh})$ ] (0.87 g, $2.25 \mathrm{mmol}), 2.5 \mathrm{M} \mathrm{n}$-butyllithium (0.9 mL, $2.25 \mathrm{mmol})$ 20 and bis(2,4,6-triisopropylphenyl) ditelluride [(TipTe) $)_{2}$ (1.49 g, $2.25 \mathrm{mmol}$ ) to afford the target compound as a cream solid. An analytically pure sample was obtained from recrystallisation by diffusion of hexane into a saturated solution of the compound in dichloromethane $(0.80 \mathrm{~g}, 56 \%)$; mp $158-160{ }^{\circ} \mathrm{C}$; elemental 25 analysis (Found: $\mathrm{C}, 61.8$; H, 5.8. Calc. for $\mathrm{C}_{33} \mathrm{H}_{36} \mathrm{SeTe}$ : C, 62.0; $\mathrm{H}, 5.7 \%) ;{ }^{1} \mathrm{H} \mathrm{NMR}\left(300 \mathrm{MHz}, \mathrm{CDCl}_{3}, 25^{\circ} \mathrm{C}, \mathrm{Me}_{4} \mathrm{Si}\right) \delta=8.05(1$ $\mathrm{H}, \mathrm{d},{ }^{3} J_{\mathrm{HH}}$ 7.1, Acenap 4-H), 7.41-7.38 (2 H, m, SePh H-27,31), $7.28\left(1 \mathrm{H}, \mathrm{d},{ }^{3} J_{\mathrm{HH}}\right.$ 7.1, Acenap 3-H), 7.26-7.21 (4 H, m, Acenap 7-H, SePh 28,29,30-H), 7.20 (2 H, s, TeTip 13,15-H), 7.02 (1 H, ${ }_{30} \mathrm{~d},{ }^{3} J_{\mathrm{HH}} 7.4$, Acenap 8-H), $3.73\left(2 \mathrm{H}\right.$, hept, ${ }^{3} J_{\mathrm{HH}} 6.8$, TeTip 17,23$\mathrm{H}), 3.43-3.35\left(4 \mathrm{H}, \mathrm{m}, 2 \times \mathrm{CH}_{2}\right), 3.04\left(1 \mathrm{H}\right.$, hept, $\left.{ }^{3} J_{\mathrm{HH}} 6.9,20-\mathrm{H}\right)$, $1.40\left(6 \mathrm{H}, \mathrm{d},{ }^{3} J_{\mathrm{HH}} 6.9\right.$, TeTip $\left.2 \times \mathrm{CH}_{3}\right), 1.21\left(12 \mathrm{H}, \mathrm{d},{ }^{3} J_{\mathrm{HH}} 6.8\right.$, TeTip 4 x C $\left.\mathrm{CH}_{3}\right) ;{ }^{77} \mathrm{Se} \mathrm{NMR}\left(51.5 \mathrm{MHz}, \mathrm{CDCl}_{3}, 25{ }^{\circ} \mathrm{C}\right.$, $\mathrm{PhSeSePh}): \delta=345$ (s, $\left.J_{\mathrm{SeTe}} 688\right) ;{ }^{125} \mathrm{Te}$ NMR $(85.2 \mathrm{MHz}$, $\left.{ }_{35} \mathrm{CDCl}_{3}, 25{ }^{\circ} \mathrm{C}, \mathrm{PhTeTePh}\right): \delta=376$ (s, $\left.J_{\mathrm{TeSe}} 688\right)$; MS $\left(\mathrm{ES}^{+}\right): \mathrm{m} / z$ $671.12(100 \%, \mathrm{M}+\mathrm{OMe})$.

\section{5-(naphthyltelluro)-6-(phenylselenyl)acenapthene}

[Acenap(TeNap)(SePh)] (9): Experimental as for compound 2 40 but with [Acenap $(\mathrm{Br})(\mathrm{SePh})](0.79 \mathrm{~g}, 2.03 \mathrm{mmol}), 2.5 \mathrm{M} n$ butyllithium $(0.81 \mathrm{~mL}, 2.03 \mathrm{mmol})$ and bis(1-naphthyl) ditelluride $\left[(\mathrm{NapTe})_{2}\right](1.04 \mathrm{~g}, 2.03 \mathrm{mmol})$ to afford the target compound as a light brown solid. An analytically pure sample was obtained from recrystallisation by diffusion of hexane into a 45 saturated solution of the compound in dichloromethane $(0.97 \mathrm{~g}$, $86 \%$ ); mp 126-128 ${ }^{\circ} \mathrm{C}$; elemental analysis (Found: C, 59.5; H, 3.7. Calc. for $\mathrm{C}_{28} \mathrm{H}_{20} \mathrm{SeTe}$ : C, 59.7; H, 3.6\%); ${ }^{1} \mathrm{H}$ NMR (300 $\left.\mathrm{MHz}, \mathrm{CDCl}_{3}, 25^{\circ} \mathrm{C}, \mathrm{Me}_{4} \mathrm{Si}\right) \delta=8.25\left(1 \mathrm{H}, \mathrm{dd},{ }^{3} J_{\mathrm{HH}} 6.9,{ }^{4} J_{\mathrm{HH}} 1.2\right.$, TeNap 14-H), 8.16 (1 H, d, ${ }^{3} J_{\mathrm{HH}}$ 7.8, TeNap 15-H), $7.91(1 \mathrm{H}, \mathrm{d}$, ${ }_{50}{ }^{3} J_{\mathrm{HH}} 7.1$, Acenap 4-H), $7.86\left(1 \mathrm{H}, \mathrm{d},{ }^{3} J_{\mathrm{HH}} 8.2\right.$, TeNap 12-H), 7.73 $\left(1 \mathrm{H}, \mathrm{d},{ }^{3} J_{\mathrm{HH}}\right.$ 7.5, TeNap 18-H), 7.41-7.34 (1 H, m, TeNap 17-H), 7.32-7.27 (2 H, m, TeNap 17,13-H), 7.26-7.21 (2 H, m, SePh 20,24-H), 7.17-7.07 (3 H, m, SePh 21,22,23-H), 6.97 (1 H, d, ${ }^{3} J_{\mathrm{HH}}$ 7.4, Acenap 7-H), $6.67\left(1 \mathrm{H}, \mathrm{d},{ }^{3} J_{\mathrm{HH}} 7.4\right.$, Acenap 8-H), 3.29${ }_{55} 3.16$ (4 H, m, Acenap 9,10-H); ${ }^{77} \mathrm{Se} \mathrm{NMR} \mathrm{(51.5} \mathrm{MHz,} \mathrm{CDCl}_{3}, 25$ $\left.{ }^{\circ} \mathrm{C}, \mathrm{PhSeSePh}\right): \delta=400$ (s, $\left.J_{\mathrm{TeSe}} 724\right) ;{ }^{125} \mathrm{Te} \mathrm{NMR}(85.2 \mathrm{MHz}$, $\left.\mathrm{CDCl}_{3}, 25^{\circ} \mathrm{C}, \mathrm{PhTeTePh}\right): \delta=552\left(\mathrm{~s}, J_{\mathrm{TeSe}} 724\right) ; \mathrm{MS}\left(\mathrm{ES}^{+}\right): \mathrm{m} / \mathrm{z}$ $580.98(100 \%, \mathrm{M}+\mathrm{O}), 595.00(70, \mathrm{M}+\mathrm{OMe})$.

\section{Solid-state NMR experimental details}

${ }_{60}{ }^{77} \mathrm{Se}$ and ${ }^{125}$ Te Solid state NMR were performed using a Bruker Avance III spectrometer operating at a magnetic field strength of 9.4 $\mathrm{T}$, corresponding to Larmor frequencies of $76.3\left({ }^{77} \mathrm{Se}\right)$ and $126.2\left({ }^{125} \mathrm{Te}\right) \mathrm{MHz}$. Experiments were carried out using conventional 4- and 1.9-mm MAS probes, with MAS rates

${ }_{65}$ between 5 and $40 \mathrm{kHz}$. Chemical shifts are referenced relative to $\left(\mathrm{CH}_{3}\right)_{2} \mathrm{Se}$ at $0 \mathrm{ppm}$ using the isotropic resonance of solid $\mathrm{H}_{2} \mathrm{SeO}_{3}$ at $1288.1 \mathrm{ppm}$ as a secondary reference, and to $\left(\mathrm{CH}_{3}\right)_{2} \mathrm{Te}$ at 0 ppm using the isotropic resonance of solid $\mathrm{Te}(\mathrm{OH})_{6}$ (site 1) at $692.2 \mathrm{ppm}$ as a secondary reference. Transverse magnetization 70 was obtained by cross polarization (CP) from ${ }^{1} \mathrm{H}$ using optimized contact pulse durations of 8-20 ms, and two-pulse phase modulation (TPPM) ${ }^{1} \mathrm{H}$ decoupling during acquisition. Spectra were acquired with recycle intervals of between 3 and $90 \mathrm{~s}$, depending on the longitudinal relaxation time of the samples. The 75 position of the isotropic resonances within the spinning sidebands patterns were unambiguously determined by recording a second spectrum at a higher MAS rate. A more detailed description of the experimental parameters for individual materials is given in the Supporting Information.

\section{${ }_{80}$ Crystal structure analyses}

$\mathrm{X}$-ray crystal structures for 2, 4-6, 8 and 9 were determined at $-148(1){ }^{\circ} \mathrm{C}$ using a Rigaku MM007 high-brilliance RA generator (Mo $\mathrm{K} \alpha$ radiation, confocal optic) and Saturn CCD system. At least a full hemisphere of data was collected using $\omega$ scans. 85 Intensities were corrected for Lorentz, polarization, and absorption. Data for compounds $\mathbf{3}$ and $\mathbf{7}$ were collected at $-100(1){ }^{\circ} \mathrm{C}$ using a Rigaku MM007 high-brilliance RA generator (Mo $\mathrm{K} \alpha$ radiation, confocal optic) and Mercury CCD system. At least a full hemisphere of data was collected using $\omega$ scans. Data 90 for the complexes analyzed was collected and processed using CrystalClear (Rigaku). ${ }^{33}$ Structures were solved by direct methods $^{34}$ and expanded using Fourier techniques. ${ }^{35}$ Nonhydrogen atoms were refined anisotropically. Hydrogen atoms were refined using the riding model. All calculations were 95 performed using the CrystalStructure ${ }^{36}$ crystallographic software package except for refinement, which was performed using SHELXL-97. ${ }^{37}$ These X-ray data can be obtained free of charge via www.ccdc.cam.ac.uk/conts/retrieving.html or from the Cambridge Crystallographic Data Centre, 12 Union Road, ${ }_{100}$ Cambridge CB2 1EZ, UK; fax (+44) 1223-336-033; e-mail: deposit@ccdc.cam.ac.uk.

\section{Computational details}

Geometries were fully optimised in the gas phase at the B3LYP/SDD/6-31G(d) level (compound 1 also with the PBE0 105 functional, see ESI for details). Wiberg bond indices ${ }^{22}$ were obtained in a natural bond orbital analysis ${ }^{31}$ at the same level and NMR spin-spin coupling constants $J\left({ }^{125} \mathrm{Te},{ }^{77} \mathrm{Se}\right)$ were calculated at the ZORA-SO/BP86/TZ2P level using the B3LYP optimised structures (Tables 1 and 2). ${ }^{27}$

\section{Acknowledgements}

Elemental analyses were performed by Stephen Boyer at the London Metropolitan University. Mass spectrometry was performed by Caroline Horsburgh at the University of $\mathrm{St}$ 
Andrews Mass Spectrometry Service. The author(s) would like to acknowledge the use of the EPSRC UK National Service for Computational Chemistry Software (NSCCS) at Imperial College London in carrying out this work. Calculations were performed 5 using the EaStCHEM Research Computing Facility maintained by Dr. H. Früchtl and a Silicon Graphics Altix cluster at NSCCS. The work in this project was supported by the Engineering and Physical Sciences Research Council (EPSRC). M.B. wishes to thank EaStCHEM and the University of St Andrews for support.

\section{${ }_{10}$ Conclusions}

A combination of X-ray crystallography, solution and solid state NMR spectroscopy and density functional theory (DFT) calculations has been used to investigate how substituents at the phenyl ring affect the bonding interactions and hence the value of 15 spin-spin coupling constants between formally non bonded Te and $\mathrm{Se}$ atoms in Acenap(TeY)(SePh) (Y = Fp 2; Tol 3; An-p 4; An-o 5; Tp 6; Mes 7; Tip 8; Nap 9).

All eight compounds, except $\mathbf{5}$, align the $\mathrm{Te}-\mathrm{C}_{\mathrm{Y}}$ bond along the mean acenaphthene plane and the $\mathrm{Se}-\mathrm{C}_{\mathrm{Ph}}$ bond perpendicular 20 (type BA), promoting a nonbonded $\mathrm{Se} \cdots \mathrm{Te}-\mathrm{C}_{\mathrm{Y}} 3 \mathrm{c}-4 \mathrm{e}$ type interaction which stabilises the molecule (G-dependence). In 5 (Y $=$ An-o), a minor rotation around the Se- $\mathrm{C}_{\text {Acenap }}$ bond affords a $\mathrm{BC}$ type conformation in the solid, however, DFT calculations show this optimises to BA configuration, and only lies $0.6 \mathrm{kcal}$ $25 \mathrm{~mol}^{-1}$ above the fully optimised minimum.

A significant through-space intramolecular peri-interaction is observed between Te and Se atoms in all compounds of the study, with substantial $J\left({ }^{125} \mathrm{Te},{ }^{77} \mathrm{Se}\right)$ SSCCs in the range $-687 \mathrm{~Hz}$ to -749 $\mathrm{Hz}$ detected in the ${ }^{77} \mathrm{Se}$ and ${ }^{125} \mathrm{Te}$ NMR spectra. Splittings of a 30 similar magnitude were observed in the isotropic peaks of solidstate ${ }^{77} \mathrm{Se}$ MAS NMR spectra, although the presence of a significant chemical shielding anisotropy prevents easy determination of the full interaction tensors.

Natural bond orbital analysis affirms the onset of 3c-4e type 35 bonding, showing a noticeable donor-acceptor interaction between a p-type lone pair on $\mathrm{Se}$ and a $\sigma^{*}(\mathrm{Te}-\mathrm{C})$ antibonding orbital which reinforces the Te,Se couplings. The crystallographic steric parameter $(\theta)$, which is the cone angle measured from the furthest $\mathrm{H}$ atoms lying on the edges of the 40 cone to the Te atom located at its vertex, was introduced to quantify the steric bulk of the aryl groups (Y). Modification to the size and electronics of $\mathrm{Y}$ has no apparent influence on the conformation of the molecule, the degree of molecular distortion occurring in the acenaphthene backbone or the extent of $3 \mathrm{c}-4 \mathrm{e}$ 45 interaction; peri-distances are within $0.08 \AA$ and no apparent correlation is observed between $\theta$ and the ${ }^{77} \mathrm{Se}$ chemical shifts or $J(\mathrm{Te}, \mathrm{Se}) \mathrm{SSCC}$. Good correlation is found, however, between $\theta$ and ${ }^{125} \mathrm{Te}$ chemical shifts. DFT calculations performed on all members of the series confirm the comparable covalent bonding 50 between Te and Se in the series, with WBIs of $c a$. 0.1 obtained, although this value is slightly lower than in bis-tellurium species, indicating a reduction in multicenter bonding.

\section{Notes and references}

${ }^{a}$ EaStCHEM School of Chemistry and Centre for Magnetic Resonance, 55 University of St Andrews, St Andrews KY16 9ST (UK). Fax: (+44)1334 463808; Tel:(+44)1334 463854; E-mail:jdw3@st-andrews.ac.uk
$†$ Electronic Supplementary Information (ESI) available: Full experimental details, computational details, X-ray crystal structure data; tables and figures. CCDC 889480-889485. See DOI: 10.1039/b000000x/

60

1 W. Kemp, NMR in Chemistry; A Multinuclear Introduction, Macmillan Education Ltd., Hampshire, England, 1986.

2 R. V. Parish, NMR, NQR, EPR, and Mössbauer Spectroscopy in Inorganic Chemistry, Ed. J. Burgess; Ellis Horwood, Chichester, England, 1990.

3 L. Ernst, P. Sakhaii, Magn. Reson. Chem. 2000, 38, 559.

4 L. Ernst, K. Ibrom, Angew. Chem. Int. Ed. Engl. 1995, 34, 1881.

5 F. B. Mallory, C. W. Mallory, K. E. Butler, M. Beth Lewis, A. Qian Xia, E. D. Luzik, Jr., L. E. Fredenburgh, M. M. Ramanjulu, Q. N. Van, M. M. Francl, D. A. Freed, C. C. Wray, C. Hann, M. NerzStormes, P. J. Carroll, L. E. Chirlian, J. Am. Chem. Soc. 2000, 122, 4108.

6 J. E. Peralta, V. Barone, R. H. Contreras, D. G. Zaccari, J. P. Snyder, J. Am. Chem. Soc. 2001, 123, 9162.

757 S. A. Reiter, S. D. Nogai, K. Karaghiosoff, H. Schmidbaur, J. Am. Chem. Soc. 2004, 126, 15833.

8 W. Nakanishi, S. Hayashi, Chem. Eur. J. 2008, 14, 5645.

9 P. Kilian, F. R. Knight. J. D. Woollins, Chem. Eur. J. 2011, 17, 2302.

10 P. Kilian, A. M. Z. Slawin, J. D. Woollins, Phosphorus Sulfur Silicon Relat. Elem. 2004, 179, 999.

11 R. D. Jackson, S. James, A. G. Orpen, P. G. Pringle, J. Organomet. Chem. 1993, 458, C3-C4.

12 P. Kilian, D. Philp, A. M. Z. Slawin, J. D. Woollins, Eur. J. Inorg. Chem. 2003, 249. (b) P. Kilian, A. M. Z. Slawin, J. D. Woollins,

85 Chem. Eur. J. 2003, 9, 215. (c) P. Kilian, A. M. Z. Slawin, J. D. Woollins, Chem. Commun. 2003, 1174. (d) P. Kilian, H. L. Milton, A. M. Z. Slawin, J. D. Woollins, Inorg. Chem. 2004, 43, 2252. (e) P. Kilian, A. M. Z. Slawin, J. D. Woollins, Inorg. Chim. Acta 2005, 358, 1719. (f) P. Kilian, A. M. Z. Slawin, J. D. Woollins, Dalton Trans. 2006, 2175. (g) P. Kilian, A. M. Z. Slawin, J. D. Woollins, Dalton Trans. 2003, 3876.

13 F. R. Knight, A. L. Fuller, M. Bühl, A. M. Z. Slawin and J. D. Woollins, Chem. Eur. J. 2010, 16, 7503.

14 F. R. Knight, A. L. Fuller, M. Bühl, A. M. Z. Slawin and J. D. Woollins, Chem. Eur. J. 2010, 16, 7605.

15 F. R. Knight, A. L. Fuller, M. Bühl, A. M. Z. Slawin and J. D. Woollins, Chem. Eur. J. 2010, 16, 7617.

16 F. R. Knight, A. L. Fuller, M. Bühl, A. M. Z. Slawin and J. D. Woollins, Inorg. Chem., 2010, 49, 7577. (b) F. R. Knight, K. S. Athukorala Arachchige, R. A. M. Randall, M. Bühl, A. M. Z. Slawin, J. D. Woollins, Dalton Trans. 2012, 41, 3154.

17 L. K. Aschenbach, F. R. Knight, R. A. M. Randall, D. B. Cordes, A. Baggott, M. Bühl, A. M. Z. Slawin, J. D. Woollins, Dalton Trans. 2012, 41, 3141

10518 F. R. Knight, R. A. M. Randall, K. S. Athukorala Arachchige, L. Wakefield, J. M. Griffin, S. E. Ashbrook, M. Bühl, A. M. Z. Slawin, J. D. Woollins, Inorg. Chem. 2012, 51, 11087.

19 M.-L. Lechner, K. S. Athukorala Arachchige, R. A. M. Randall, F. R. Knight, M. Bühl, A. M. Z. Slawin, J. D. Woollins, Organometallics 2012, 31, 2922

20 M. Bühl, F. R. Knight, A. Křístková, I. Malkin Ondík, O. L. Malkina, R. A. M. Randall, A. M. Z. Slawin, J. D. Woollins, Angew. Chem. 2013, 125, 2555; Angew. Chem. Int. Ed. 2013, 52, 2495.

21 F. R. Knight, R. A. M. Randall, T. L. Roemmele, R. T. Boeré, B. E. 115 Bode, L. Crawford, M. Bühl, A. M. Z. Slawin, J. D. Woollins, ChemPhyChem, 2013, 14, 3199.

22 K. B. Wiberg, Tetrahedron, 1968, 24, 1083-1096.

23 H. Fujihara, H. Ishitani, Y. Takaguchi, N. Furukawa, Chem. Lett. 1995, 24, 571.

12024 The magnetic equivalence of the two Te nuclei in solution impedes direct observation of $J\left({ }^{125} \mathrm{Te},{ }^{125} \mathrm{Te}\right)$ couplings in ${ }^{125} \mathrm{Te}$ NMR spectra, however, they can be converted from experimentally obtained $J\left({ }^{123} \mathrm{Te},{ }^{125} \mathrm{Te}\right)$ coupling detected as satellites in the ${ }^{123} \mathrm{Te}$ NMR.

25 W. Nakanishi, S. Hayashi, S. Toyota, Chem. Commun. 1996, 371;

125 W. Nakanishi, S. Hayashi, A. Sakaue, G. Ono, Y. Kawada, J. Am. Chem. Soc. 1998, 120, 3635; W. Nakanishi, S. Hayashi, S. Toyota, J. Org. Chem. 1998, 63, 8790; S. Hayashi, W. Nakanishi, J. Org. Chem. 
1999, 64, 6688; W. Nakanishi, S. Hayashi, T. Uehara, J. Phys. Chem. 1999, 103, 9906; W. Nakanishi, S. Hayashi, Phosphorus, Sulfur, Silicon Relat. Elem. 2002, 177, 1833; S. Hayashi, W. Nakanishi, J. Org. Chem. 2002, 67, 38; S. Hayashi, W. Nakanishi, Bull. Chem.

5 Soc. Jpn. 2008, 81, 1605; S. Hayashi, K. Yamane, W. Nakanishi, Bioinorganic Chemistry and Applications 2009, 2009, doi:10.1155/2009/347359; T. Nakai, M. Nishino, S. Hayashi, M. Hashimoto, W. Nakanishi, Dalton Trans. 2012, 41, 7485.

26 P. Nagy, D. Szabó, I. Kapovits, Á. Kucsman, G. Argay, A. Kálmán, 10 J. Mol. Struct. 2002, 606, 61.

27 Employing the same level as in: ref 20.

28 Couplings involving different sets of nuclei are best compared in terms of reduced coupling constants $\mathrm{K}$; for $1,8-\mathrm{C}_{10} \mathrm{H}_{6} \mathrm{X}_{2}$ the following $K$ values are obtained at the ZSO/BP86/TZ2P level (in $10^{19} \mathrm{~kg} \mathrm{~m}^{-2} \mathrm{~s}^{-2}$

$15 \mathrm{~A}^{-2}$, in bold $): \mathrm{X}=\mathrm{F}, \boldsymbol{K}\left({ }^{\mathbf{1 9}} \mathbf{F},{ }^{\mathbf{1 9}} \mathbf{F}\right)=\mathbf{3 . 7}(J=38.9 \mathrm{~Hz}) ; \mathrm{X}=\mathrm{PMe}_{2}$, $K\left({ }^{31} \mathbf{P},{ }^{31} \mathbf{P}\right)=107.8(J=213 \mathrm{~Hz}) ; \mathrm{X}=\mathrm{SeMe}, K\left({ }^{77} \mathrm{Se},{ }^{77} \mathrm{Se}\right)=\mathbf{7 7 6}(\mathrm{CC} t$ isomer, $J=341 \mathrm{~Hz}) ; \mathrm{X}=\mathrm{TeMe}, \boldsymbol{K}\left({ }^{125} \mathrm{Te},{ }^{125} \mathrm{Te}\right)=\mathbf{2 2 2 0}(\mathrm{CC} t$ isomer, $\mathrm{J}$ $=2691 \mathrm{~Hz}$ ). By moving down one row in the periodic table, $K$ increases significantly, for example, by a factor of three between the

$20 \quad$ Se and Te congeners.

29 C. A. Tolman, J. Am. Chem. Soc. 1970, 92, 2953; C. A. Tolman, J. Am. Chem. Soc. 1970, 92, 2956; C. A. Tolman, Chem. Rev. 1977, 77, 313.

30 A. Bondi, J. Phys. Chem. 1964, 68, 441

2531 A. E. Reed, F. Curtiss and L. A. F. Weinhold, Chem. Rev., 1988, 88, 899.

32 M. Oba, Y. Okada, M. Endo, K. Tanaka, K. Nishiyama, S. Shimada, W. Ando, Inorg. Chem. 2010, 49, 10680.

33 CrystalClear 1.6: Rigaku Corporation, 1999. CrystalClear Software

30 User's Guide, Molecular Structure Corporation, (c) 2000. Flugrath, J. W. P. Acta Crystallogr., Sect. D 1999, D55, 1718.

34 SIR97: A. Altomare, M. Burla, M. Camalli, G. Cascarano, C. Giacovazzo, A. Guagliardi, A. Moliterni, G. Polidori, R. Spagna, J. Appl. Cryst. 1999, 32, 115.

3535 DIRDIF99: P. T. Beurskens, G. Admiraal, G. Beurskens, W. P. Bosman, R. de Gelder, R. Israel, J. M. M. Smits, 1999. The DIRDIF99 program system, Technical Report of the Crystallography Laboratory, University of Nijmegen, The Netherlands.

36 CrystalStructure 3.8.1: Crystal Structure Analysis Package, Rigaku

$40 \quad$ and Rigaku/MSC (2000-2006). 9009 New Trails Dr. The Woodlands TX 77381 USA.

37 SHELX97: G. M. Sheldrick, Acta Crystallogr., Sect. A 2008, 64, 112. 